Check for updates

Cite this: Dalton Trans., 2017, 46, 11768

Received 26th July 2017,

Accepted 7th August 2017

DOI: $10.1039 / \mathrm{c} 7 \mathrm{dt02729j}$

rsc.li/dalton

\title{
Dissimilar catalytic behavior of molecular or colloidal palladium systems with a new $\mathrm{NHC}$ ligand $\uparrow$
}

\author{
Fernando Gómez-Villarraga, $\ddagger^{a}$ Jonathan De Tovar, (D) $\ddagger^{a}$ Miguel Guerrero, (D) b,c \\ Pau Nolis, (D) ${ }^{d}$ Teodor Parella, ${ }^{d}$ Pierre Lecante, (D) e Nuria Romero, (D) ${ }^{a}$ \\ Lluís Escriche, ${ }^{a}$ Roger Bofill, ${ }^{a}$ Josep Ros, ${ }^{a}$ Xavier Sala, (D) ${ }^{a}$ Karine Philippot (D)*b,c and \\ Jordi García-Antón (D) *a
}

\begin{abstract}
In this work, we describe the synthesis of a new $\mathrm{N}$-heterocyclic carbene (NHC) ligand, derived from a hybrid pyrazole-imidazolium scaffold, namely 1-[2-(3,5-dimethylpyrazol-1-yl)ethyl]-3-((S)-1-phenylethyl)-3H-imidazol-2-ylidene (L). This ligand has been used as a stabilizer for the organometallic synthesis of palladium( $(0)$ nanoparticles (Pd NPs). L presents a better stabilizing effect than its pre-carbenic $\mathrm{HLCl}$ counterpart, allowing the formation of isolated Pd NPs while $\mathrm{HLCl}$ yields aggregated ones. Additionally, molecular $\mathrm{Pd}(\|)$ coordination compounds of $\mathbf{L}$ and $\mathbf{H L C l}$ were synthesized and characterized to better understand the coordination modes of these ligands. Both molecular and colloidal Pd systems have been further tested in catalytic $\mathrm{C}-\mathrm{C}$ coupling processes. Three different types of reactions have been observed depending on the catalytic system: (i) the Suzuki-Miyaura reaction takes place with Pd molecular complexes; (ii) a secondary reaction, the dehalogenation of the substrate, is always detected and (iii) the $\mathrm{C}-\mathrm{C}$ homocoupling between two molecules of bromoarenes is observed with colloidal catalysts.
\end{abstract}

\section{Introduction}

During the last few years, the use of N-heterocyclic carbenes (NHCs) as primary ligands has emerged in catalysis and beyond. Amongst other catalytic processes, organometallic compounds containing these ligands have been applied in the cross-coupling reactions of un-activated substrates. ${ }^{1}$ This can be explained not only by their remarkably strong $\sigma$-binding and steric tunability, ${ }^{2}$ but also by their ability to stabilize highly unusual and hitherto elusive reactive species such as metal nanoparticles (MNPs) thanks to their stability under

\footnotetext{
${ }^{a}$ Departament de Quimica, Unitat de Quimica Inorgànica, Facultat de Ciències, Universitat Autònoma de Barcelona, 08193-Bellaterra, Barcelona, Spain. E-mail: Jordi.GarciaAnton@uab.es; Fax: (+34) 935813101

${ }^{b}$ CNRS, LCC (Laboratoire de Chimie de Coordination du CNRS), 205, route de Narbonne, F-31077 Toulouse, France.E-mail: Karine.Philippot@lcc-toulouse.fr; Fax: (+33) 561553003

${ }^{c}$ Université de Toulouse, UPS, INPT, LCC, F-31077 Toulouse, France

${ }^{d}$ Servei de Ressonància Magnètica Nuclear, Facultat de Ciències, Universitat Autònoma de Barcelona, 08193 Cerdanyola del Vallès, Barcelona, Catalonia, Spain ${ }^{e}$ CNRS, CEMES (Centre d'Elaboration de Matériaux et d'Etudes Structurales), 29 rue J. Marvig, F-31055 Toulouse, France

$\dagger$ Electronic supplementary information (ESI) available. CCDC 1432563. For ESI and crystallographic data in CIF or other electronic format see DOI: 10.1039/ c7dt02729j

$\$$ These authors equally contributed to this work.
}

oxidative conditions once coordinated. ${ }^{3}$ Thus, NHCs have become ligands of paramount importance in nanochemistry given their advantageous behavior for the stabilization and functionalization of MNPs. ${ }^{4}$ Although different families of NHCs have been largely explored in various important organic transformations when combined with metal pre-catalysts, imidazolium salts are the most frequently employed as the core structures for NHCs given their straightforward syntheses and feasible tuning properties. ${ }^{5}$

Different methodologies can be followed to obtain and stabilize NPs in different media while controlling their size, shape and composition, which, in turn, can tune their unique properties. ${ }^{6}$ The use of coordinating ligands is of particular interest to prepare MNPs because it gives the possibility of modulating their surface properties as known for the synthesis of molecular complexes. ${ }^{7}$ As a consequence, ligandstabilized MNPs became very attractive for applications in catalysis. ${ }^{8}$ MNPs are able to catalyze not only reactions that can also be catalyzed by molecular complexes (i.e. C-C coupling or hydrogenation of olefins) but also reactions that cannot be catalyzed by molecular complexes (i.e. hydrogenation of arenes).

Furthermore, palladium is the most versatile transition metal in chemical catalytic reactions since many of these processes cannot be catalyzed by other transition metals. ${ }^{9}$ Thus, $\operatorname{Pd}(0)$ NPs have shown large catalytic efficiency in C-C coupling 
reactions specially when non-aggregated homogeneous NPs of 1-4 $\mathrm{nm}$ size are used as catalysts. ${ }^{10}$

The Suzuki-Miyaura reaction is one of the most important cross-coupling processes from an industrial point of view. ${ }^{11}$ It allows to easily obtain biaryl products, important intermediates in the organic syntheses of various target products ranging from performance materials to pharmaceuticals. ${ }^{12}$ Although noble metal complexes are usually employed as catalysts for this reaction, MNPs merit study since playing with stabilizing ligands may tune their catalytic performance. ${ }^{13}$

Our research group has focused on discerning the catalytic behavior of colloidal and molecular palladium systems in $\mathrm{C}-\mathrm{C}$ coupling reactions. For example, we have recently studied Pd molecular/colloidal systems containing new hybrid pyrazole derived ligands with alkylether, alkylthioether or alkylamino moieties leading to different catalytic outputs depending on the system. ${ }^{14}$ Here we present improved Pd systems based on a new NHC-pyrazole hybrid ligand. Interestingly, as it will be described hereafter, different behaviors were observed in $\mathrm{C}-\mathrm{C}$ coupling catalysis that illustrates the possibility of optimizing the catalytic system according to the final aim.

\section{Results and discussion}

\section{Synthesis of the ligand (L)}

For the synthesis of 1-[2-(3,5-dimethylpyrazol-1-yl)ethyl]-3- $((S)$ 1-phenylethyl)-3H-imidazol-1-ium chloride (HLCl), 1-(2-chloroethyl)-3,5-dimethyl- $1 H$-pyrazole and 1-(S)-(phenylethyl)imidazole were heated solventless at $120{ }^{\circ} \mathrm{C}$ for $64 \mathrm{~h}$. The deprotonation of HLCl to yield 1-[2-(3,5-dimethylpyrazol-1-yl)ethyl]3-((S)-1-phenylethyl)-3H-imidazol-2-ylidene (L) was achieved by reacting HLCl with $\mathrm{NaH}$ and a catalytic amount of ${ }^{t} \mathrm{BuOK}$ in anhydrous dichloromethane (Scheme 1). Both $\mathbf{L}$ and HLCl have been fully characterized by NMR and IR spectroscopies as well as by ESI-MS (Fig. S1-S6 in the ESI $\dagger$ ).

\section{Synthesis of $\operatorname{Pd}(0)$ nanoparticles (Pd NPs)}

Ligand $\mathbf{L}$ has been used to prepare Pd NPs according to the organometallic approach under mild reaction conditions. ${ }^{15}$ The syntheses have been carried out by reacting $\left[\mathrm{Pd}_{2}(\mathrm{dba})_{3}\right]$ $(\mathrm{dba}=$ dibenzylideneacetone $)$ and $\mathbf{L}([\mathbf{L}] /[\mathrm{Pd}]$ molar ratios varying from 0.1 to 1.0 ) in anhydrous dichloromethane for $18 \mathrm{~h}$ in a Fisher-Porter reactor, under 3 bar of dihydrogen at room temperature. Finally, Pd NPs were precipitated and washed with cold pentane and dried under reduced pressure.

TEM (transmission electron microscopy) and SEM (scanning electron microscopy) analyses (after deposition/drying of a drop of crude colloidal solutions onto a holey carboncovered copper grid) were performed with all the obtained samples. The results showed that the Pd NPs are aggregated into superstructures when a L/Pd ratio of 0.1 is used (HR-TEM images are shown in Fig. 1a and SEM-FEG images are shown in ESI, Fig. S7a $\dagger$ ). The single NPs are spherical and have a mean size of 3.6(0.9) $\mathrm{nm}$ but the superstructures do not have a preferential shape and their size varies from 50 to $250 \mathrm{~nm}$. For
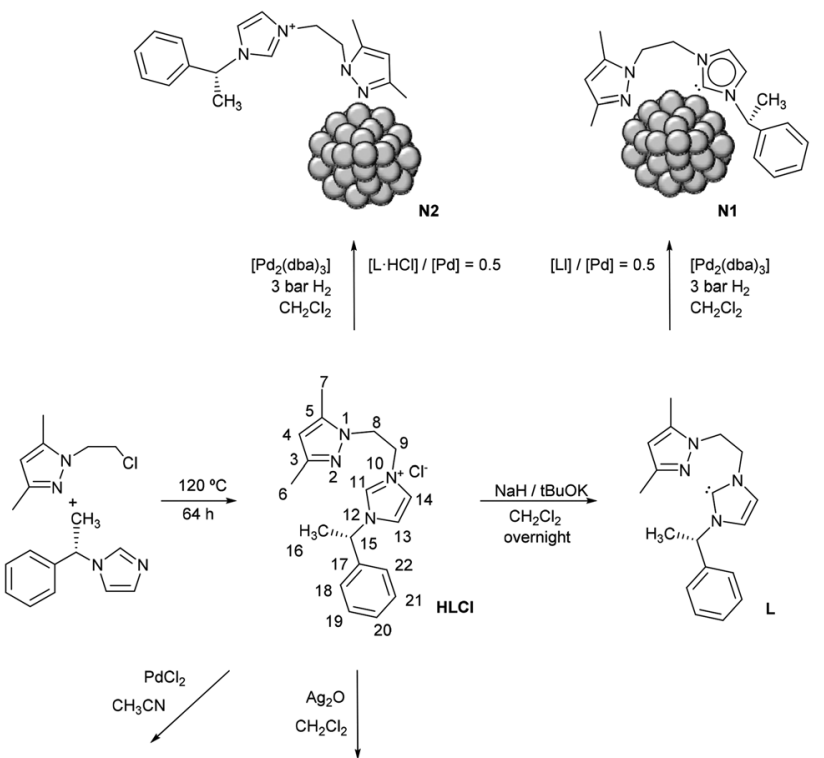

$\mathrm{Ag}_{2} \mathrm{O}$
$\mathrm{CH}_{2} \mathrm{Cl}_{2}$
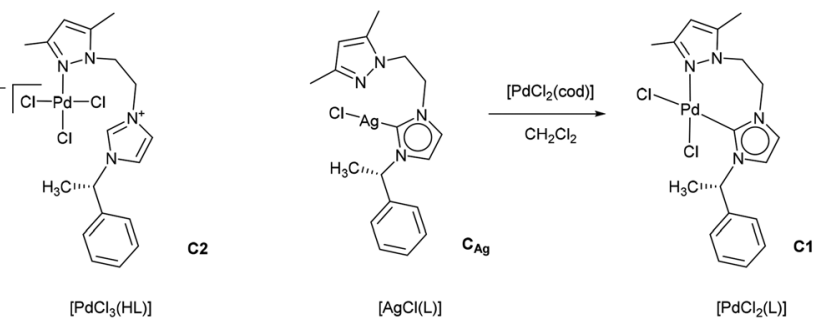

Scheme 1 Synthetic preparation of $\mathrm{L}$ and $\mathrm{HLCl}$ and their corresponding $\mathrm{Ag}$ and $\mathrm{Pd}$ molecular complexes $\left(\mathrm{C}_{\mathrm{Ag}}, \mathrm{C} 1\right.$ and $\left.\mathrm{C} 2\right)$ and $\mathrm{Pd}$ nanoparticulate systems (N1 and N2).

L/Pd ratios of $0.3,0.5$ and 1.0, only isolated NPs were observed (Fig. 1b-d). In all these cases, NPs are spherical and present similar mean sizes in the range of 2.1-2.4 nm. These similar sizes indicate that a minimum $\mathbf{L} / \mathrm{Pd}$ molar ratio of 0.3 is needed to have stable isolated NPs, but the addition of a higher ligand/metal ratio does not have a significant effect on the size of the NPs.

For comparative purposes, the stabilization of the NPs has also been attempted with the protonated ligand HLCl (see HR-TEM images in Fig. 2 and SEM-FEG images in ESI, Fig. S7b-d $\dagger$ ). In this case, a molar ratio of 0.1 failed to afford stable NPs. For molar ratios of 0.3 and 0.5 Pd NPs appeared organized into superstructures, and for the molar ratio of 1.0, a mixture of isolated and aggregated NPs was observed. The mean sizes of these NPs are 3.0(0.7), 3.2(0.9) and 2.1(0.9) nm for $\mathbf{H L C l} / \mathrm{Pd}$ molar ratios of $0.3,0.5$ and 1.0, respectively. Therefore, with HLCl a higher ratio of ligand is needed to successfully stabilize the NPs. From these results and given the main difference of the two ligands ( $\mathbf{L}$ is a carbene while $\mathbf{H L C l}$ is not deprotonated), we believe that the stabilization of the Pd NPs takes place by the coordination of $\mathbf{L}$ through the carbene $(\mathrm{M}-\mathrm{C})$ and pyrazolic $(\mathrm{M}-\mathrm{N})$ groups to the surface of the Pd NPs whereas HLCl would only coordinate through the pyrazolic group (Scheme 1). 

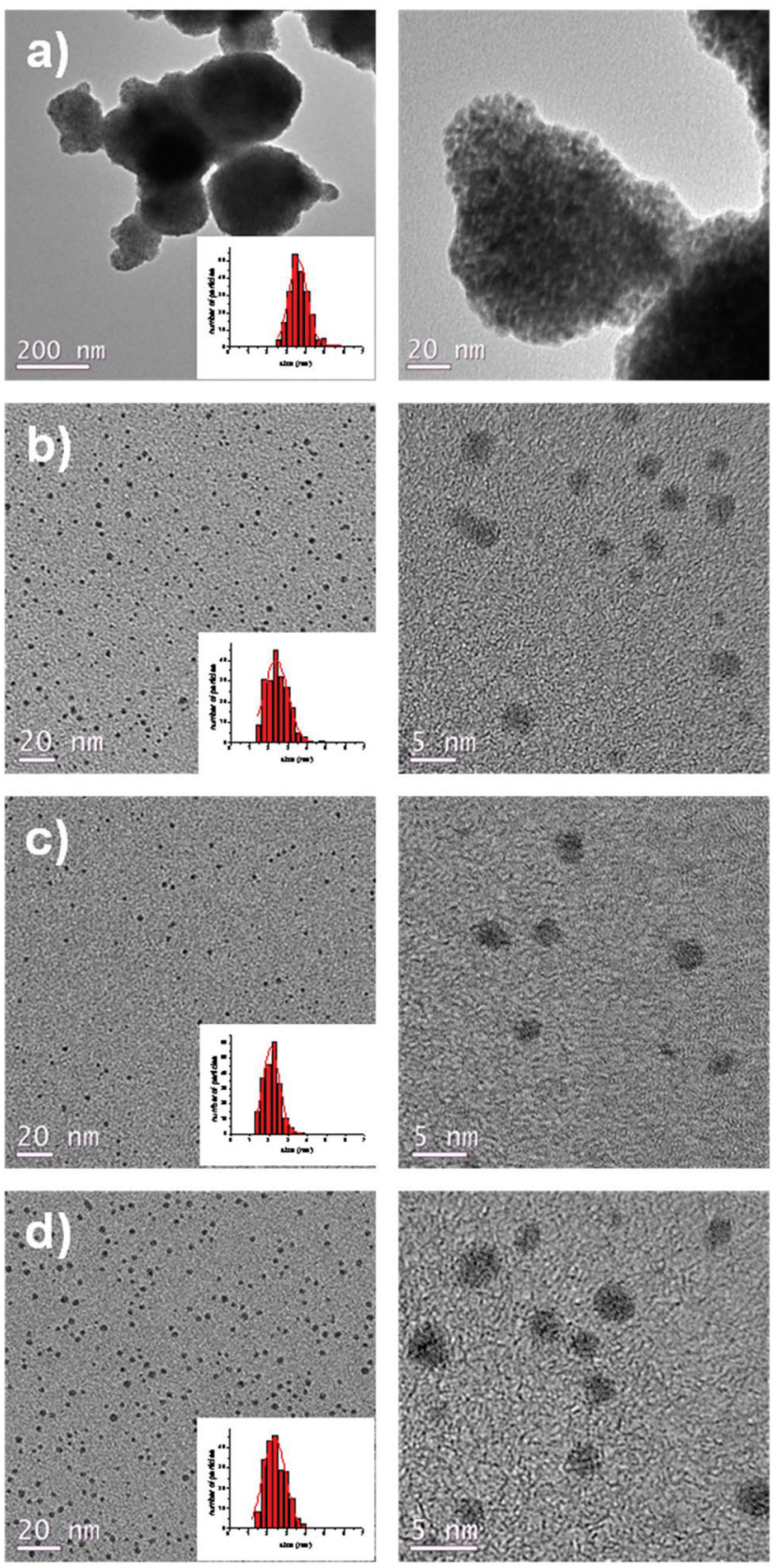

Fig. 1 HR-TEM micrographs and the corresponding size-histograms of Pd nanoparticles stabilized with $L$ synthesized as follows: (a) $[\mathrm{L}] /[\mathrm{Pd}]=$ $0.1 ;(b)[L] /[P d]=0.3 ;$ (c) $[\mathrm{L}] /[\mathrm{Pd}]=0.5 ;$ (d) $[\mathrm{L}] /[\mathrm{Pd}]=1.0$.

The presence of the ligands $\mathbf{L}$ or $\mathbf{H L C l}$ in $\mathbf{N} 1$ or $\mathbf{N} 2$ (those prepared with $\mathbf{L}$ and $\mathbf{H L C l}$, respectively, in a ligand/Pd molar ratio equal to 0.5 ) has been demonstrated by IR spectroscopy (Fig. $\mathrm{S} 8 \dagger$ and the Experimental section), and ICP-OES and elemental analyses. The Pd/ligand ratios found are $\operatorname{Pd}_{561} \mathrm{~L}_{37}$ and $\mathrm{Pd}_{1415} \mathrm{HLCl}_{93}$ for $\mathbf{N} 1$ and $\mathbf{N} 2$, respectively.

Wide-angle X-ray scattering (WAXS) measurements have been performed on nanoparticles $\mathbf{N} 1$ and $\mathbf{N} 2$. The two radial distribution functions (RDFs) (Fig. 3a) are very similar and in good agreement with the fcc structure of bulk Pd. However, significant distances can be observed of at least up to $4 \mathrm{~nm}$,
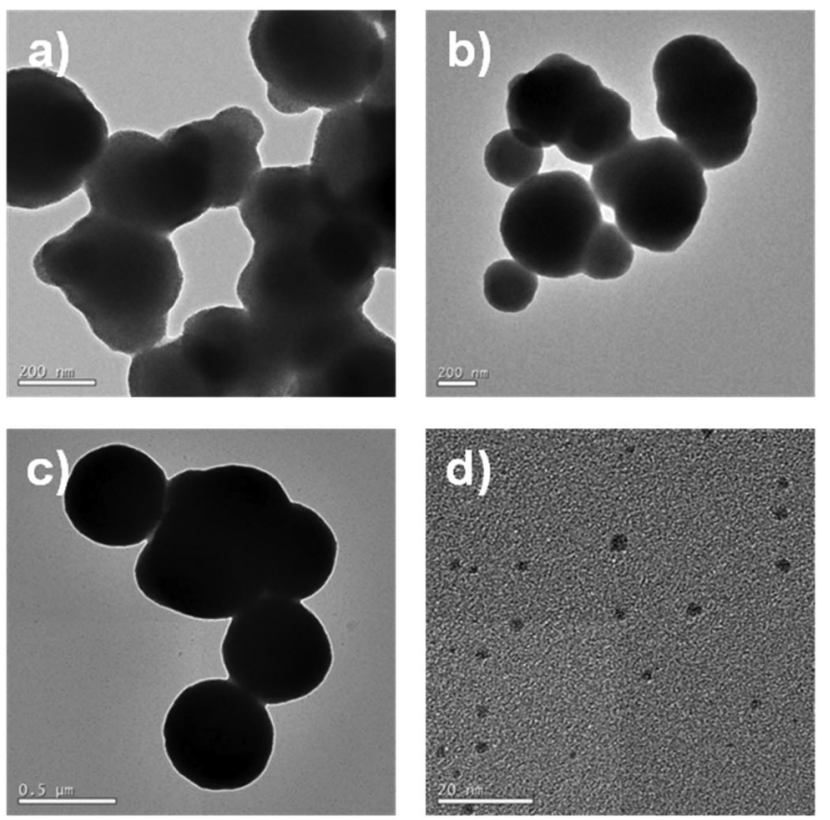

Fig. 2 HR-TEM micrographs and the corresponding size-histograms of $\mathrm{Pd}$ nanoparticles stabilized with $\mathrm{HLCl}$ synthesized as follows: (a) $[\mathrm{HLCl}] /[\mathrm{Pd}]=0.3$; (b) $[\mathrm{HLCl}] /[\mathrm{Pd}]=0.5$; (c) and (d) $[\mathrm{HLCl}] /[\mathrm{Pd}]=1.0$.

thus being in disagreement with the sizes obtained from HR-TEM (2.1(0.9) and 3.2(0.9) for $\mathbf{N} 1$ and $\mathbf{N} 2$, respectively). Indeed, when compared with the RDF computed (Fig. 3b) from a spherical model $2.0 \mathrm{~nm}$ in diameter, the agreement does not go beyond $1.5 \mathrm{~nm}$. A much better result can be obtained with a dual size model, including a small amount $(10 \%)$ of much bigger spherical particles (5 $\mathrm{nm}$ in diameter). Actually, this dual size model is likely itself oversimplified and different combinations including a large majority of $2 \mathrm{~nm}$ particles and a minority of bigger ones should probably lead to the same level of agreement. This result, however, is not in contradiction with the TEM results taking into account not only the mean sizes but also the relatively large tail on the bigger size side.

\section{Synthesis and characterization of Pd(II) molecular complexes (C1-C2)}

$\operatorname{Pd}(\mathrm{II})$ molecular complexes of $\mathbf{L}$ and $\mathbf{H L C l}$ have been synthesized in order to better understand the coordination properties of these ligands (Scheme 1).

The silver carbene transmetallation reaction is a general procedure for the preparation of palladium-carbene complexes ${ }^{16}$ and was considered to obtain the Pd complex with $\mathbf{L}$. The silver complex of $\mathbf{L}\left(\mathbf{C}_{\mathbf{A g}}\right)$ was prepared by reacting silver dioxide and HLCl in anhydrous dichloromethane. The ${ }^{1} \mathrm{H}$ NMR spectrum of this complex shows that the pre-carbene proton of the imidazolium salt is no longer present, thus confirming the deprotonation of the imidazolium group and formation of the Ag-NHC bond (Fig. 4 and Fig. S9†). Also, the formation of $\mathbf{C}_{\mathrm{Ag}}$ has been confirmed by ESI-MS and IR spectroscopy (Fig. S10 and S11, $\uparrow$ respectively). The next step consisted of the reaction of $\mathbf{C}_{\mathbf{A g}}$ with $\left[\mathrm{PdCl}_{2}(\operatorname{cod})\right]$ in anhydrous 

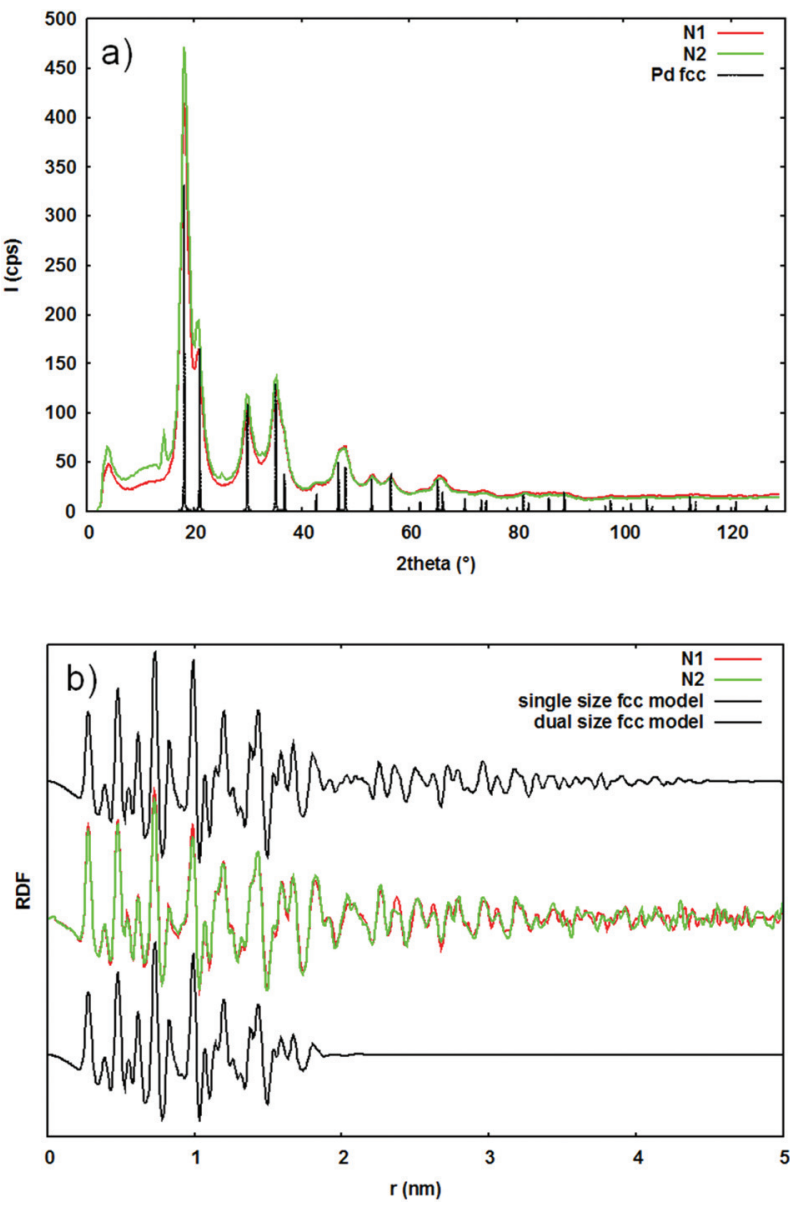

Fig. 3 WAXS measurements on Pd nanoparticles for N1 and N2 and comparison with $\mathrm{Pd} \mathrm{fcc}$ in reciprocal space (a) and real space including simulated from a model including only $2 \mathrm{~nm}$ particles based on the Pd fcc structure (lower) and simulated from a model including $2 \mathrm{~nm}$ particles plus $10 \%$ of $5 \mathrm{~nm}$ particles (upper) (b).

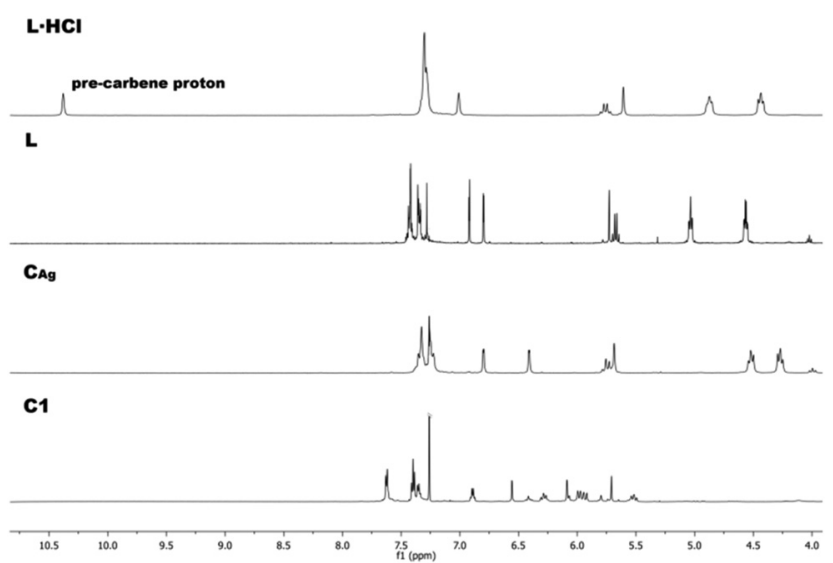

Fig. $4{ }^{1} \mathrm{H}-\mathrm{NMR}$ of $\mathrm{HLCl}, \mathrm{L}$ and $\mathrm{C}_{\mathrm{Ag}}$ registered at $360 \mathrm{MHz}\left(\mathrm{CDCl}_{3}\right.$, $298 \mathrm{~K})$ and $\mathrm{C} 1$ registered at $600 \mathrm{MHz}\left(\mathrm{CDCl}_{3}, 298 \mathrm{~K}\right)$.

dichloromethane (Scheme 1) to obtain the carbenic $\mathrm{Pd}$ complex $\left[\mathrm{PdCl}_{2} \mathrm{~L}\right](\mathbf{C 1})$. The absence of the pre-carbene proton in the ${ }^{1} \mathrm{H}$-NMR spectrum of $\mathbf{C 1}$ confirms the formation of the
Pd-NHC bond (Fig. 4 and Fig. S12†). The formation of the complex has been attested by HR-ESI-MS and IR spectroscopy (Fig. S13 and S14, $\uparrow$ respectively). Moreover, the NMR data also evidence the chelation of the ligand to the metallic centre through the NHC and pyrazolic groups. The rigidity imposed by this coordination mode causes the two protons of each $\mathrm{CH}_{2}$ in the $\mathrm{N}-\mathrm{CH}_{2} \mathrm{CH}_{2}-\mathrm{N}$ moiety $\left(\mathrm{H}_{8}\right.$ and $\left.\mathrm{H}_{9}\right)$ to become diastereotopic, resulting in four visible signals assigned to a single hydrogen atom each (see high-resolution NMR spectra of $\mathbf{C 1}$ including ${ }^{1} \mathrm{H}$ and ${ }^{13} \mathrm{C}$ NMR spectroscopy chemical shift assignments in Fig. S12a and $\mathrm{b}_{\dagger} \dagger$ ). It is also noticeable that some proton signals split, which is a single quote labeled in Fig. S12a. $\dagger$ This splitting is due to conformational exchange between a major and a minor component with a ratio of approximately 70/30, as deduced from signal integration.

In order to study further this chemical exchange process, a 2D ROESY (Rotating Frame Overhauser Effect Spectrocopy) spectrum was recorded. ${ }^{17}$ Briefly explained, in this NMR experiment ROE and occasionally chemical exchange cross peaks are observed. ${ }^{18}$ The former are indicative of through space distance proximity, and the latter are detected when protons experience distinct chemical environments, which is commonly the case when a conformational equilibrium is present. The distinction of the above mentioned different cross peaks families is possible from the opposite signal phase in the ROESY spectrum. Fig. 5 and S12d $\dagger$ show the 2D ROESY spectrum of $\mathbf{C 1}$, where chemical exchange cross peaks are detected in the negative phase (blue color), while ROE cross peaks are positive phased (red color). Thus, protons $\mathrm{H}_{8}$ and $\mathrm{H}_{9}$ in the ethyl chain undergo a pronounced chemical environment exchange, with cross peaks situated notably separated from the spectrum diagonal. This conformational exchange

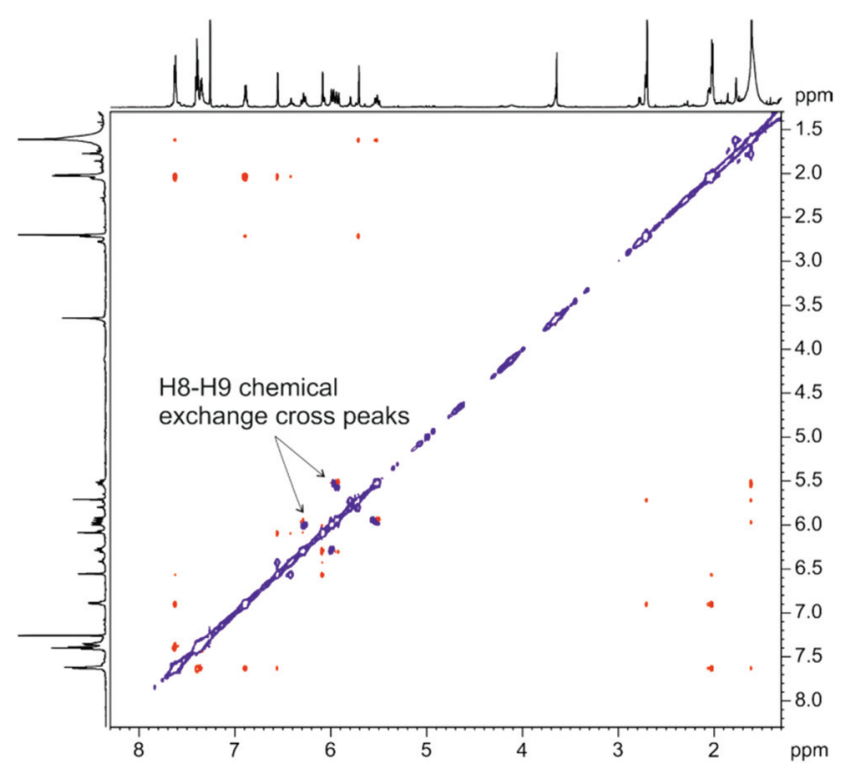

Fig. 5 2D ROESY spectrum of $\mathrm{C} 1$ registered at $600 \mathrm{MHz}\left(\mathrm{CDCl}_{3}, 298 \mathrm{~K}\right)$. Arrows pointing negative cross peaks (blue color) indicate chemical exchange between $\mathrm{H}_{8}$ and $\mathrm{H}_{9}$ protons. 
might be explained on the basis of a slow conformational equilibrium of the new seven-membered ring formed. Other protons $\left(\mathrm{H}_{4}, \mathrm{H}_{6}, \mathrm{H}_{7}, \mathrm{H}_{13}, \mathrm{H}_{14}\right.$ and $\left.\mathrm{H}_{16}\right)$ also exhibit chemical exchange cross peaks, which are closer to the spectrum diagonal, indicating that chemical exchange is taking place between less differentiated chemical environments. This latter effect could be explained as a side-effect from the mentioned seven ring conformational exchange. On the other side, neither benzyl ring protons $\mathrm{H}_{18}-\mathrm{H}_{22}$ nor $\mathrm{H}_{15}$ show any chemical exchange cross peaks, suggesting that these protons are situated far enough from the conformational exchange described.

On the other hand, the direct reaction of $\mathbf{H L C l}$ with $\mathrm{PdCl}_{2}$ in acetonitrile yielded the complex $\left[\mathrm{PdCl}_{3}(\mathrm{HL})\right](\mathbf{C} 2$, Scheme 1), which has been characterized by NMR and IR spectroscopies and ESI-MS (Fig. S15-S17†), thus confirming its stoichiometry. Interestingly, the existence of the protonated ligand $\mathbf{H L}^{+}$is confirmed by the singlet ${ }^{1} \mathrm{H}$ NMR spectroscopy resonance appearing at $9.03 \mathrm{ppm}$ for the $\mathrm{H}_{11}$ pre-carbene proton (Fig. S15†).

Crystal and molecular structure of trichloro $[(S)-$ 3-(2-(3,5-dimethyl-1H-pyrazol-1-yl)ethyl)-1-(1-phenylethyl)$1 H$-imidazol-3-ium- $\left.\kappa^{1} \mathrm{~N}\right]$ palladium(II) (C2)

Single crystals of $\mathbf{C 2}$ suitable for X-ray diffraction analysis were obtained by slow evaporation of a concentrated acetonitrile solution of the complex at RT. The structure of $\mathbf{C} 2$ consists of monomeric $\left[\mathrm{PdCl}_{3}(\mathrm{HL})\right]$ units (Fig. 6a), linked by van der Waals forces (Fig. 6b). The palladium center is coordinated by three terminal chloride ligands and one pyrazolic nitrogen from a 1-[2-(3,5-dimethylpyrazol-1-yl)ethyl]-3-((S)-1-phenylethyl)$3 H$-imidazol-1-ium cation in a slightly distorted square-planar geometry. Crystallographic data are listed in Table $\mathbf{S} 1, \uparrow$ and the data on selected bond lengths and angles are gathered in Table S2. $\uparrow$ The positive charge generated by the imidazolium cation is canceled by the negative charge provided by the third chloride ion coordinated to Pd(II), thus forming a zwitterionic structure.

There are three complexes reported in the literature with a $\mathrm{PdCl}_{3} \mathrm{~N}$ core (terminal chloride ligands and pyrazolic nitrogen). ${ }^{19-21}$ The $\mathrm{Pd}-\mathrm{N}$ and $\mathrm{Pd}-\mathrm{Cl}$ bond lengths here observed are comparable to the values found in the literature, and the $\mathrm{N}-\mathrm{Pd}-\mathrm{Cl}$ and $\mathrm{Cl}-\mathrm{Pd}-\mathrm{Cl}$ bond angles slightly deviate from the square planar angles (Table $\mathrm{S} 2 \dagger$ ).

In compound $\mathbf{C 2}$, chlorine atoms ( $\mathrm{Cl} 2$ and $\mathrm{Cl} 3$, Fig. 6b) form three different hydrogen bonds: C3-H3A …Cl2 (2.707 А, $\left.146.11^{\circ}\right)$ and $\mathrm{C} 15-\mathrm{H} 15 \cdots \mathrm{Cl} 3\left(2.935 \AA, 154.30^{\circ}\right)$ interacting with hydrogens from the ethylene group of an adjacent $\mathbf{C 2}$ unit, and $\mathrm{C} 11-\mathrm{H} 11 \cdots \mathrm{Cl} 2\left(2.840 \AA, 138.45^{\circ}\right)$ interacting with a hydrogen atom from the imidazole aromatic ring of another adjacent $\mathbf{C 2}$ complex. These interactions are responsible for the expansion in the crystallographic a direction.

\section{Catalytic experiments with Pd molecular or colloidal systems}

C1 and C2 Pd complexes (with $\mathbf{L}$ and HLCl ligands, respectively) as well as N1 and N2 Pd nanoparticles have been evalu- a)

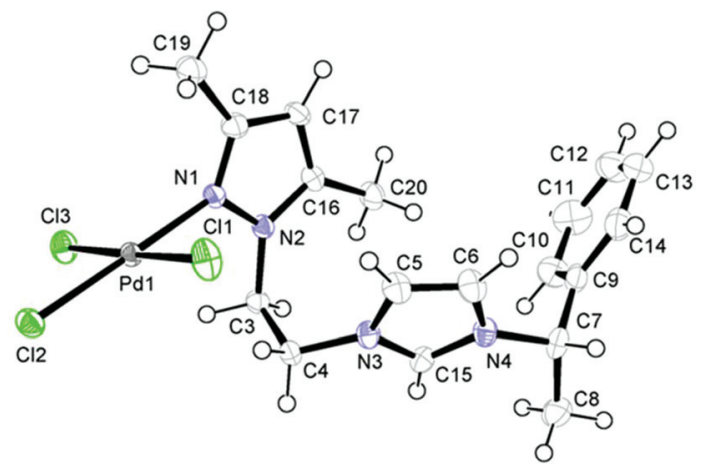

b)

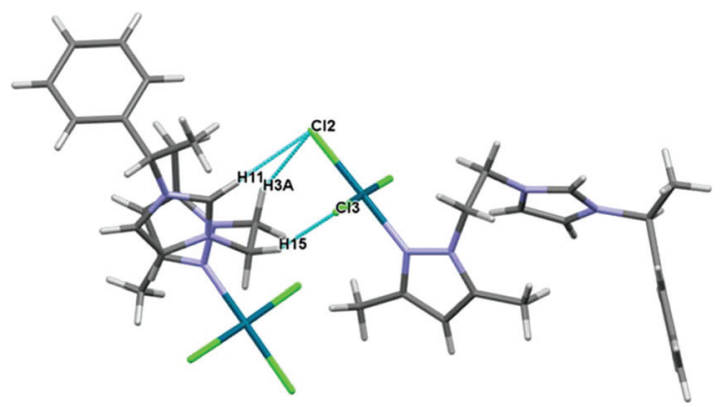

Fig. 6 ORTEP drawing of C2, showing the atom-numbering scheme; $50 \%$ probability amplitude displacement ellipsoids are shown for all non-hydrogen atoms (a) and hydrogen interactions present in the unit cell of C2 (b)

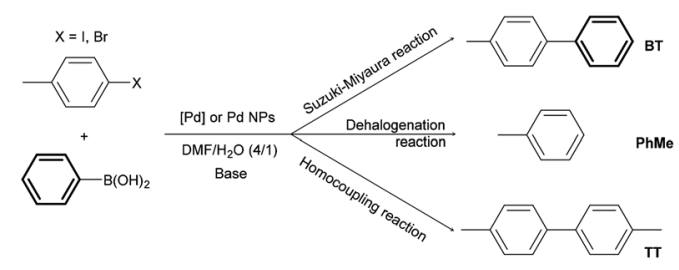

Scheme 2 Suzuki-Miyaura, homocoupling and dehalogenation reactions performed in the presence of Pd complexes $\mathrm{C} 1$ and $\mathrm{C} 2$ and Pd NPs N1 and N2.

ated as catalysts for the Suzuki-Miyaura reaction (Scheme 2, Table 1). ${ }^{22,23}$

4-Halogenotoluene derivatives (4-chlorotoluene, 4-bromotoluene or 4-iodotoluene) and an excess of phenylboronic acid were chosen as substrates in order to easily distinguish between cross-coupling and homocoupling products. Under the catalytic reaction conditions applied (Scheme 2), ${ }^{14}$ two different by-products can be formed besides the expected cross-coupled product (4-methylbiphenyl; BT) as follows: (i) toluene (PhMe) arising from the dehalogenation of the substrates and (ii) 4,4'-dimethylbiphenyl (TT), resulting from the 4-bromotoluene homocoupling. Once optimized, 4-halogenotoluene (substrate/Pd $=2500)$, phenylboronic acid $\left(\mathrm{PhB}(\mathrm{OH})_{2} /\right.$ $\mathrm{Pd}=3125$ or 0 ), and ${ }^{t} \mathrm{BuOK}$ (base/Pd $=5000$ ) were employed in a DMF/water mixture (4/1) as the solvent. As a general trend, 
Table 1 Suzuki-Miyaura reactions with palladium catalysts ${ }^{a}$

\begin{tabular}{|c|c|c|c|c|c|c|c|c|c|}
\hline Entry & Catalyst & $\mathrm{X}$ & {$\left[\mathrm{PhB}(\mathrm{OH})_{2}\right] /[\mathrm{Pd}]$} & $\begin{array}{l}\text { Conv. }{ }^{b} \\
(\%)\end{array}$ & $\begin{array}{l}\text { BT }^{c} \\
(\%)\end{array}$ & $\begin{array}{l}\mathrm{TT}^{c} \\
(\%)\end{array}$ & $\begin{array}{l}\mathrm{PhMe}^{c} \\
(\%)\end{array}$ & $\begin{array}{l}\text { Yield } \\
\text { BT (\%) }\end{array}$ & $\begin{array}{l}\text { Yield } \\
\text { TT (\%) }\end{array}$ \\
\hline 1 & C1 & I & 3125 & 100 & 51 & 0 & 49 & 51 & 0 \\
\hline 3 & C1 & $\mathrm{Br}$ & 3125 & 28 & 71 & 0 & 29 & 20 & 0 \\
\hline 4 & $\mathrm{C} 2$ & $\mathrm{Br}$ & 3125 & 46 & 93 & 0 & 7 & 43 & 0 \\
\hline 5 & N1 & I & 3125 & 100 & 81 & 0 & 19 & 81 & 0 \\
\hline 8 & N2 & I & 0 & 56 & 0 & 0 & 56 & 0 & 0 \\
\hline 9 & N1 & $\mathrm{Br}$ & 3125 & 66 & 5 & 51 & 44 & 3 & 34 \\
\hline 10 & N2 & $\mathrm{Br}$ & 3125 & 36 & 7 & 37 & 56 & 3 & 13 \\
\hline 11 & N1 & $\mathrm{Br}$ & 0 & 72 & 0 & 83 & 17 & 0 & 60 \\
\hline 12 & N2 & $\mathrm{Br}$ & 0 & 36 & 0 & 72 & 28 & 0 & 26 \\
\hline
\end{tabular}

${ }^{a}$ Reaction conditions: $1 \times 10^{-3} \mathrm{mmol}$ of Pd, $2.5 \mathrm{mmol}$ of 4 -halogenotoluene, $5.0 \mathrm{mmol}{ }^{t} \mathrm{BuOK}$ and $0.5 \mathrm{mmol}$ naphthalene as an internal standard in $8.0 \mathrm{~mL}$ of DMF and $2.0 \mathrm{~mL}$ of $\mathrm{H}_{2} \mathrm{O}$. Temperature, $100{ }^{\circ} \mathrm{C} .{ }^{b}$ Conversion after $6 \mathrm{~h}$ reaction. ${ }^{c}$ Chemoselectivity in 4 -methylbiphenyl (BT), $4,4^{\prime}$-dimethylbiphenyl (TT) and toluene (PhMe), respectively.

higher conversions were obtained with 4-iodotoluene compared to 4-bromotoluene in both molecular and colloidal systems (Table 1), as expected from the respective $\mathrm{C}(\mathrm{Ph})-\mathrm{X}$ bond energies $\left(\mathrm{X}=\mathrm{Br}, 84 \mathrm{kcal} \mathrm{mol}^{-1} ; \mathrm{X}=\mathrm{I}, 67 \mathrm{kcal} \mathrm{mol}^{-1}\right) .^{24}$ Unfortunately, 4-chlorotoluene could not be activated probably due to the higher $\mathrm{C}(\mathrm{Ph})-\mathrm{Cl}$ bond energy value $\left(97.1 \mathrm{kcal} \mathrm{mol}^{-1}\right)^{24}$ and the Suzuki-Miyaura coupling reaction was unsuccessful.

Interestingly, in the presence of the molecular catalysts C1 and $\mathbf{C 2}$, toluene was the only side product observed in a significant amount using both 4-bromotoluene and 4-iodotoluene as substrates (Table 1, entries 1-4). The homocoupling reaction does not take place, as otherwise predictable according to the literature on Pd molecular complexes. ${ }^{14}$ Also, 4-bromotoluene yields BT as the major product, while the amount of the dehalogenation product (toluene) significantly increases when 4-iodotoluene is used.

Recently, V. P. Ananikov et al. have demonstrated the formation of Pd NPs when molecular Pd complexes with NHC ligands are used in the Mizoroki-Heck reaction. ${ }^{25}$ In our case, even if it is not a definite proof, TEM control analyses of the solutions after catalysis with $\mathbf{C} 1$ or $\mathbf{C} 2$ did not show the presence of Pd nanoparticles. In any case, Hg poisoning tests carried out using these systems (vide infra) confirm the molecular nature of the real catalyst when $\mathbf{C} 1$ or $\mathbf{C} 2$ is used.

When 4-iodotoluene was used as a substrate with nanocatalysts $\mathbf{N} 1$ and $\mathbf{N} 2$, complete conversions were achieved in $6 \mathrm{~h}$ in both cases. In the case of $\mathbf{N} 1$, the formation of the cross-coupling product (4-methylbiphenyl; BT) was mainly observed together with a small amount of toluene (Table 1, entry 5). The formation of toluene increases to $53 \%$ in the case of N2 (Table 1, entry 6). In contrast, $\mathbf{N} 1$ and $\mathbf{N} 2$ behave similarly against 4-bromotoluene, with the formation of 4,4'-dimethylbiphenyl (TT), arising from the homocoupling reaction, together with toluene and small amounts of BT (Table 1, entries 9 and 10). Furthermore, for the two halogenotoluene substrates, both conversion and chemoselectivities are higher for the Pd NP/L system (N1) than that for the Pd NP/HLCl system (N2). These differences can be explained by the binding of the carbene group at the Pd NP surface in the case of N1 compared to N2. Indeed, the different coordination modes (by $\mathrm{C}$ and $\mathrm{N}$ in $\mathbf{N} 1$ and only by $\mathrm{N}$ in $\mathbf{N} 2$ ) may tune both electronic and steric properties at the surface and consequently the catalytic behavior of $\mathbf{N 1}$.

In order to determine the influence of phenylboronic acid in $\mathrm{C}-\mathrm{C}$ coupling reactions catalyzed by the colloidal systems, catalytic experiments were also carried out in the absence of the boron reagent. Besides that BT was not detected, it is remarkable that full conversion to the dehalogenated product $(\mathrm{PhMe})$ is observed in the case of the reaction carried out with 4-iodotoluene catalyzed by N1 (Table 1, entry 7). However, when 4-bromotoluene was employed a significant increase in the yield of the TT homocoupling product is observed for both nanocatalysts (from $34 \%$ to $60 \%$; Table 1, entries 9 and 11 , respectively, for N1, and from $13 \%$ to $26 \%$ for N2, entries 10 and 12). When performed with the molecular complexes, the same reaction of 4-halotoluene in the absence of phenylboronic acid reagent did not yield homocoupling products at all.

A recurrent discussion with Pd NPs as catalysts for C-C coupling reactions is whether the real catalysts are the NPs or molecular Pd species leached from them. ${ }^{10}$ There are several publications that support either a surface-based ${ }^{26}$ or atomleaching mechanism. ${ }^{27}$ In this context, three different tests have been carried out to assess the nature of the active species during the catalytic process. First of all, in the mercury poisoning test, ${ }^{28} 100$ equivalents of $\mathrm{Hg}$ were added to the catalytic mixtures after $10 \mathrm{~min}$ of reaction. For molecular systems (C1 and C2) the conversions were not affected, while for the colloidal systems (N1 and $\mathbf{N} 2)$ the catalytic reactions ceased completely. These data suggest that $\mathbf{C} \mathbf{1}$ and $\mathbf{C 2}$ act as real molecular catalysts when starting with them, whereas Pd NPs are the active species when $\mathbf{N} \mathbf{1}$ and $\mathbf{N} \mathbf{2}$ are introduced into the catalysis. This is in accordance with the different results observed in catalysis depending on the molecular or colloidal 
nature of the introduced catalysts. However, the mercury poisoning test is not definitive, since the amalgam of $\mathrm{Hg}$ and Pd from the NPs could prevent potential Pd molecular species from leaching. For this reason, additional experiments have been performed with systems from entries 9 and 10 in Table 1 (Suzuki-Miyaura reaction conditions, $p$-bromotoluene as the haloderivative and $\mathbf{N} 1$ or $\mathbf{N} 2$ as the catalyst, respectively). First of all, TEM grids were prepared after the catalytic experiments, observing the existence of Pd NPs (Fig. S18 $\dagger$ ). The mean size of these NPs (2.7(0.7) and 3.3(0.6) nm for N1 and N2 after catalysis, respectively) is similar to those found for the same NPs prior to the catalytic tests (2.1(0.9) and 3.2(0.9) $\mathrm{nm}$ for $\mathbf{N 1}$ or $\mathbf{N} 2$, respectively). Even if no restructuring of the NPs seems to have taken place (which could indicate a leaching/deposition mechanism through the Ostwald ripening process ${ }^{29}$ ), it is important to note that for $\mathbf{N} 2$ the NPs appear isolated after catalysis, in contrast with the aggregation observed prior to catalysis.

Secondly, ICP-MS analyses of the solutions after catalysis for entries 9 and 10 in Table 1 were carried out in order to know the amount of Pd leached from the NPs to the solution. The concentrations of $\mathrm{Pd}$ in these solutions are 0.17 and $1.8 \mathrm{ppm}$ for $\mathbf{N} 1$ or $\mathbf{N} 2$, respectively, meaning that $0.7 \%$ and $15 \%$ of Pd have leached to the solution for $\mathbf{N} 1$ or $\mathbf{N} 2$, respectively. The differences on the percentage of leached Pd can be explained by the different coordinative properties of the ligands on each system. For N1, the carbene and pyrazolyl groups from $\mathbf{L}$ can coordinate to the surface of the NPs, and better stabilize them from Pd leaching than in N2, where only the pyrazolyl group from $\mathbf{H L C l}$ can coordinate to the surface of the NPs.

Moreover, the leached molecular Pd species can be responsible for the small amount of $\mathrm{C}-\mathrm{C}$ heterocoupling reaction observed in entries 9 and 10 of Table 1 (5\% and $7 \%$, respectively).

All in all, these experiments indicate that $\mathbf{C} 1$ and $\mathbf{C} 2$ act as molecular catalysts in Suzuki-Miyaura C-C heterocoupling and $\mathbf{N} 1$ and $\mathbf{N} 2$ are the real active species for the $\mathrm{C}-\mathrm{C}$ homocoupling reaction.

\section{Experimental section}

\section{General procedure and reagents}

All manipulations were carried out under an argon atmosphere using standard Schlenk tubes or Fisher-Porter reactors and vacuum line techniques, or in a glove-box. $\left[\mathrm{Pd}_{2}(\mathrm{dba})_{3}\right]$ was purchased from Strem Chemicals, and $\left[\mathrm{PdCl}_{2}\left(\mathrm{CH}_{3} \mathrm{CN}\right)_{2}\right]^{30}$ and $\left[\mathrm{PdCl}_{2}(\mathrm{cod})\right]^{31}$ (cod $=1,5$-cyclooctadiene) were prepared as described in the literature. Solvents were purchased from SDS and dried using a purification machine (MBraun MB SPS-800) or distilled prior to use: tetrahydrofuran and diethyl ether over sodium/benzophenone, and pentane, $n$-hexane, acetonitrile and dichloromethane over calcium hydride.

Elemental analyses (C, H, and N) were carried out by the Chemical Analyses Service of the Universitat Autònoma de
Barcelona on a Eurovector 3011 instrument. The Pd weight percentages or concentrations were analyzed by the Chemical Analyses Service of the Universitat Autònoma de Barcelona using an inductively coupled plasma mass spectrometry (ICP-MS) Agilent 7500ce model system or an inductively coupled plasma optical emission spectrometry (ICP-OES) PerkinElmer Optima 4300DV model system. Infrared spectra were recorded on a PerkinElmer FT spectrophotometer, series 2000 , as $\mathrm{KBr}$ pellets or polyethylene films in the range of 4000-150 $\mathrm{cm}^{-1} \cdot{ }^{1} \mathrm{H}$ NMR, ${ }^{13} \mathrm{C}\left\{{ }^{1} \mathrm{H}\right\}$ NMR, HSQC, COSY, DOSY and NOESY spectra for all compounds but $\mathbf{C 1}$ were recorded on Bruker AVANCE 360 and $400 \mathrm{NMR}$ spectrometers in $\mathrm{CDCl}_{3}$ solutions at room temperature. For C1, NMR spectroscopy experiments were performed on a Bruker Avance 600 spectrometer (Bruker Biospin, Rheinstetten, Germany) equipped with TXI HCN z-grad probes. The temperature for all measurements was set to $298 \mathrm{~K}$. The NMR spectroscopy experiments performed for the structural characterization were the standard ${ }^{1} \mathrm{H},{ }^{13} \mathrm{C}$, COSY, ROESY, multiplicity-edited HSQC and HMBC experiments (see the ESI $\dagger$ ). All chemical shift values $(\delta)$ are given in ppm. Electrospray ionization mass spectra (SI-MS) were obtained with an Esquire 3000 ion trap mass spectrometer from Bruker Daltonics.

Specimens for TEM/HR-TEM and SEM-FEG analyses were prepared by slow evaporation of a drop of crude colloidal solution deposited under argon onto holey carbon-covered copper grids. TEM/HR-TEM analyses were performed at the Servei de Microscopia de la UAB with a JEOL JEM 2010 electron microscope working at $200 \mathrm{kV}$ with a resolution point of $2.5 \AA$. SEM-FEG analyses were performed at the Service Commun de Microscopie Electronique de l'Université Paul Sabatier in Toulouse with an MEB JSM6700F microscope. The size distributions were determined via manual analysis of enlarged micrographs by measuring $c a .200$ particles on a given grid to obtain a statistical size distribution and a mean diameter.

Data collection for WAXS was performed at the CEMES-CNRS (Toulouse) on small amounts of powder. All samples were sealed in $1 \mathrm{~mm}$ diameter Lindemann glass capillaries. The measurements of the X-ray intensity scattered by the samples irradiated with graphite monochromatized MoK $\alpha$ $(0.071069 \mathrm{~nm})$ radiation were performed using a dedicated twoaxis diffractometer. The measurement time was $15 \mathrm{~h}$ for each sample. Scattering data were corrected for polarization and absorption effects, then normalized to one Pd atom and Fourier transformed to obtain the RDFs. To make comparisons with the crystalline structure in real space, a model was generated from bulk Pd parameters. The classic Debye's function was then used to compute the intensity values, subsequently Fourier transformed under the same conditions as the experimental ones.

\section{Synthesis and characterization of the ligands}

1-[2-(3,5-Dimethylpyrazol-1-yl)ethyl]-3-((S)-1-phenylethyl)-3Himidazol-1-ium chloride (HLCl). A mixture of 1-(2-chloroethyl)3,5-dimethyl-1H-pyrazole ${ }^{20}(0.942 \mathrm{~g}, 5.94 \mathrm{mmol})$ and 1- $(S)$ (phenylethyl)imidazole ${ }^{32}(1.023 \mathrm{~g}, 5.94 \mathrm{mmol})$ was heated and stirred at $120{ }^{\circ} \mathrm{C}$ for 64 hours. After cooling to room tempera- 
ture, the product was dissolved in dichloromethane $(5 \mathrm{~mL})$ and precipitated with diethylether $(50 \mathrm{~mL})$. For complete precipitation, the system was stored overnight at $-31{ }^{\circ} \mathrm{C}$. The product was washed with diethylether $(3 \times 30 \mathrm{~mL})$ and dried under vacuum. The product was obtained as a sticky orange solid. Yield: $1.79 \mathrm{~g}, 91 \%$.

Anal. calcd for $\mathrm{C}_{18} \mathrm{H}_{23} \mathrm{~N}_{4} \mathrm{Cl} \cdot 1.5 \mathrm{H}_{2} \mathrm{O}: \mathrm{C}, 60.41 ; \mathrm{H}, 7.32$; $\mathrm{N}, 15.66$. Found: C, 60.54; H, 7.27; N, 16.02. ${ }^{1} \mathrm{H}-\mathrm{NMR}:\left(\mathrm{CDCl}_{3}\right.$, $360 \mathrm{MHz}, 298 \mathrm{~K}) \delta: 1.89$ [s, $3 \mathrm{H}, \mathrm{H}_{6}$ or $\left.\mathrm{H}_{7}\right], 1.92\left[\mathrm{br}, 3 \mathrm{H}, \mathrm{H}_{16}\right]$, 2.06 [s, 3H, $\mathrm{H}_{6}$ or $\left.\mathrm{H}_{7}\right], 4.44\left[\mathrm{br}, 2 \mathrm{H}, \mathrm{H}_{9}\right], 4.87$ [br, $\left.2 \mathrm{H}, \mathrm{H}_{8}\right], 5.61$ $\left[\mathrm{s}, 1 \mathrm{H}, \mathrm{H}_{4}\right], 5.76\left[\mathrm{q}, 1 \mathrm{H},{ }^{3} \mathrm{~J}=7.0 \mathrm{~Hz}, \mathrm{H}_{15}\right], 7.00,7.23[2 \mathrm{br}, 1 \mathrm{H}$ each one, $\left.\mathrm{H}_{13}, \mathrm{H}_{14}\right], 7.30$ [br, $\left.5 \mathrm{H}, \mathrm{H}_{18}-\mathrm{H}_{22}\right], 10.32\left[\mathrm{~s}, 1 \mathrm{H}, \mathrm{H}_{11}\right]$. (DMSO, $360 \mathrm{MHz}, 298 \mathrm{~K}$ ) $\delta: 1.81\left[\mathrm{~d}, 3 \mathrm{H},{ }^{3} \mathrm{~J}=7.0 \mathrm{~Hz}, \mathrm{H}_{16}\right], 1.99$ $\left[\mathrm{s}, 6 \mathrm{H}, \mathrm{H}_{6}\right.$ and $\left.\mathrm{H}_{7}\right], 4.42\left[\mathrm{t}, 2 \mathrm{H},{ }^{3} \mathrm{~J}=5.0 \mathrm{~Hz}, \mathrm{H}_{9}\right], 4.58\left[\mathrm{t}, 2 \mathrm{H},{ }^{3} \mathrm{~J}=\right.$ $\left.5.0 \mathrm{~Hz}, \mathrm{H}_{8}\right], 5.73\left[\mathrm{~s}, 1 \mathrm{H}, \mathrm{H}_{4}\right], 5.83\left[\mathrm{q}, 1 \mathrm{H},{ }^{3} J=7.0 \mathrm{~Hz}, \mathrm{H}_{15}\right], 7.36$ [br, 5H, $\left.\mathrm{H}_{18}-\mathrm{H}_{22}\right], 7.72,7.92$ [2br, $1 \mathrm{H}$ each one, $\left.\mathrm{H}_{13}, \mathrm{H}_{14}\right], 9.39$ $\left[\mathrm{s}, 1 \mathrm{H}, \mathrm{H}_{11}\right] \cdot{ }^{13} \mathrm{C}\left\{{ }^{1} \mathrm{H}\right\}$-NMR: $\left(\mathrm{CDCl}_{3}, 91 \mathrm{MHz}, 298 \mathrm{~K}\right) \delta: 10.7,13.4$ $\left[\mathrm{C}_{6}, \mathrm{C}_{7}\right], 21.1\left[\mathrm{C}_{16}\right], 47.9\left[\mathrm{C}_{9}\right], 49.2\left[\mathrm{C}_{8}\right], 59.9\left[\mathrm{C}_{15}\right], 105.5\left[\mathrm{C}_{4}\right]$, $120.4,123.0\left[\mathrm{C}_{13}, \mathrm{C}_{14}\right], 126.8,129.4,137.8\left[\mathrm{C}_{17}-\mathrm{C}_{22}\right], 136.6$ $\left[\mathrm{C}_{11}\right], 140.5,148.7\left[\mathrm{C}_{3}, \mathrm{C}_{5}\right]$. (DMSO-d6, $\left.91 \mathrm{MHz}, 298 \mathrm{~K}\right) \delta: 10.2$, $13.3\left[\mathrm{C}_{6}, \mathrm{C}_{7}\right], 20.6\left[\mathrm{C}_{16}\right], 47.2\left[\mathrm{C}_{9}\right], 48.8\left[\mathrm{C}_{8}\right], 58.5\left[\mathrm{C}_{15}\right], 105.0$ $\left[\mathrm{C}_{4}\right], 121.3,123.2\left[\mathrm{C}_{13}, \mathrm{C}_{14}\right], 126.5,128.7,129.0,\left[\mathrm{C}_{17}-\mathrm{C}_{22}\right]$, $136.0\left[\mathrm{C}_{11}\right]$ 139.4, $146.8\left[\mathrm{C}_{3}, \mathrm{C}_{5}\right]$. IR (ATR) $\mathrm{cm}^{-1}: 3040,2978$ $\nu(\mathrm{C}-\mathrm{H}), 1552(\nu(\mathrm{C}=\mathrm{C}), \nu(\mathrm{C}=\mathrm{N}))$ ar, $1455(\delta(\mathrm{C}=\mathrm{C}), \delta(\mathrm{C}=\mathrm{N}))$ ar, $1160 \delta$ (C-H)ip, $703 \delta$ (C-H)oop. MS (ESI): $m / z$ (\%) 295.2 $(100.0 \%)\left[\mathrm{C}_{18} \mathrm{H}_{23} \mathrm{~N}_{4} \mathrm{Cl}-\mathrm{Cl}^{-}\right]$.

1-[2-(3,5-Dimethylpyrazol-1-yl)ethyl]-3-((S)-1-phenylethyl)$3 \boldsymbol{H}$-imidazol-2-ylidene (L). Under an argon atmosphere, sodium hydride $(60 \%$ dispersion in mineral oil, $124.1 \mathrm{mg}$, $3.10 \mathrm{mmol}$ ) was washed with anhydrous pentane twice $(2 \times 15 \mathrm{~mL})$ and the residual solvent was evaporated under reduced pressure. Then, a catalytic amount of potassium tertbutoxide $(95 \%, 10 \mathrm{mg}, 0.08 \mathrm{mmol})$ and anhydrous dichloromethane $(5 \mathrm{~mL})$ was added. A solution of 1-[2-(3,5-dimethylpyrazol-1-yl)ethyl]-3-((S)-1-phenylethyl)-3H-imidazol-1-ium chloride (HLCl, $513.2 \mathrm{mg}, 1.55 \mathrm{mmol}$ ) in anhydrous dichloromethane $(20 \mathrm{~mL})$ was added to the dispersion of $\mathrm{NaH} / \mathrm{KO}^{t} \mathrm{Bu}$. The resulting mixture was stirred overnight at room temperature. The reaction crude was then filtered through a small plug of Celite and the solvent was removed under reduced pressure. The product was obtained as a sticky dark orange solid. Yield: $333 \mathrm{mg}, 73 \%$.

${ }^{1} \mathrm{H}-\mathrm{NMR}:\left(\mathrm{CDCl}_{3}, 400 \mathrm{MHz}, 298 \mathrm{~K}\right) \delta: 2.00\left[\mathrm{~s}, 3 \mathrm{H}, \mathrm{H}_{6}\right.$ or $\left.\mathrm{H}_{7}\right]$, $2.02\left[\mathrm{~d}, 3 \mathrm{H},{ }^{3} \mathrm{~J}=7.0 \mathrm{~Hz}, \mathrm{H}_{16}\right], 2.16\left[\mathrm{~s}, 3 \mathrm{H}, \mathrm{H}_{6}\right.$ or $\left.\mathrm{H}_{7}\right], 4.55[\mathrm{t}, 2 \mathrm{H}$, $\left.{ }^{3} J=5.0 \mathrm{~Hz}, \mathrm{H}_{9}\right], 5.01\left[\mathrm{t}, 2 \mathrm{H},{ }^{3} J=5.0 \mathrm{~Hz}, \mathrm{H}_{8}\right], 5.65\left[\mathrm{q}, 1 \mathrm{H},{ }^{3} J=\right.$ $\left.7.0 \mathrm{~Hz}, \mathrm{H}_{15}\right], 5.71\left[\mathrm{~s}, 1 \mathrm{H}, \mathrm{H}_{4}\right], 6.77,6.90\left[2 \mathrm{~d}, 1 \mathrm{H}\right.$ each one, ${ }^{3} J=$ $\left.2.0 \mathrm{~Hz}, \mathrm{H}_{13}, \mathrm{H}_{14}\right]$, 7.31-7.42 [2 m, 5H, $\left.\mathrm{H}_{18}-\mathrm{H}_{22}\right] .{ }^{13} \mathrm{C}\left\{{ }^{1} \mathrm{H}\right\}-\mathrm{NMR}$ : $\left(\mathrm{CDCl}_{3}, 100 \mathrm{MHz}, 298 \mathrm{~K}\right) \delta: 10.7,13.5\left[\mathrm{C}_{6}, \mathrm{C}_{7}\right], 21.2\left[\mathrm{C}_{16}\right], 48.0$ $\left[\mathrm{C}_{9}\right], 49.2\left[\mathrm{C}_{8}\right], 60.2\left[\mathrm{C}_{15}\right], 105.6\left[\mathrm{C}_{4}\right], 120.4,123.0\left[\mathrm{C}_{13}, \mathrm{C}_{14}\right]$, $126.8,129.5,137.8\left[\mathrm{C}_{17}-\mathrm{C}_{22}\right], 140.5,148.8\left[\mathrm{C}_{3}, \mathrm{C}_{5}\right]$, signal for $\left[\mathrm{C}_{11}\right]$ was not observed. IR (ATR) $\mathrm{cm}^{-1}: 3033,2960 \nu(\mathrm{C}-\mathrm{H}), 1552$ $(\nu(\mathrm{C}=\mathrm{C}), \nu(\mathrm{C}=\mathrm{N})) \operatorname{ar}, 1454(\delta(\mathrm{C}=\mathrm{C}), \delta(\mathrm{C}=\mathrm{N}))$ ar, $1015 \delta(\mathrm{C}-\mathrm{H}) \mathrm{ip}$, $700 \delta(\mathrm{C}-\mathrm{H})$ oop.

\section{Synthesis and characterization of the $\operatorname{Pd}(\mathrm{II})$ or $\mathrm{Ag}(\mathrm{I})$ complexes}

Chloro[(S)-3-(2-(3,5-dimethyl-1H-pyrazol-1-yl)ethyl)-1-(1-phenylethyl)-1H-imidazol-2-ylidiene]silver $(\mathrm{I}), \quad\left(\mathrm{C}_{\mathrm{Ag}}\right) . \quad \mathrm{A}$ mixture of
1-[2-(3,5-dimethylpyrazol-1-yl)ethyl]-3-((S)-1-phenylethyl)-3Himidazol-1-ium chloride (HLCl, $342 \mathrm{mg}, 1.03 \mathrm{mmol}$ ) and silver (I) oxide $(99 \%, 240 \mathrm{mg}, 1.03 \mathrm{mmol})$ in anhydrous dichloromethane $(25 \mathrm{~mL})$ was stirred at room temperature for 24 hours in the dark. Then, the reaction crude was filtered through Celite. The filtrate solvent was removed under vacuum and the product was dried completely. The product was obtained as a sticky grey-brown solid. Yield: $361 \mathrm{mg}, 80 \%$.

Anal. calcd for $\mathrm{C}_{18} \mathrm{H}_{22} \mathrm{AgClN}_{4}$ : C, 49.39; H, 5.07; N, 12.80 . Found: C, 49.92; H, 5.14; N, $12.47 .{ }^{1} \mathrm{H}-\mathrm{NMR}:\left(\mathrm{CDCl}_{3}, 360 \mathrm{MHz}\right.$, $298 \mathrm{~K}) \delta: 1.77\left[\mathrm{~s}, 3 \mathrm{H}, \mathrm{H}_{6}\right.$ or $\left.\mathrm{H}_{7}\right], 1.81\left[\mathrm{br}, 3 \mathrm{H}, \mathrm{H}_{16}\right], 2.18[\mathrm{~s}, 3 \mathrm{H}$, $\mathrm{H}_{6}$ or $\mathrm{H}_{7}$ ], 4.29 [br, $2 \mathrm{H}, \mathrm{H}_{9}$ ] 4.54 [br, $2 \mathrm{H}, \mathrm{H}_{8}$ ], 5.68 [s, $1 \mathrm{H}, \mathrm{H}_{4}$ ], $5.76\left[\mathrm{br}, 1 \mathrm{H}, \mathrm{H}_{15}\right], 6.43,6.80$ [2br, $1 \mathrm{H}$ each one, $\left.\mathrm{H}_{13}, \mathrm{H}_{14}\right], 7.23$, 7.32 [2 br, $\left.5 \mathrm{H}, \mathrm{H}_{18}-\mathrm{H}_{22}\right] .{ }^{13} \mathrm{C}\left\{{ }^{1} \mathrm{H}\right\}$-NMR: $\left(\mathrm{CDCl}_{3}, 91 \mathrm{MHz}, 298 \mathrm{~K}\right)$ $\delta: 10.6,13.7\left[\mathrm{C}_{6}, \mathrm{C}_{7}\right], 21.4\left[\mathrm{C}_{16}\right], 49.3\left[\mathrm{C}_{9}\right], 51.9\left[\mathrm{C}_{8}\right], 60.9\left[\mathrm{C}_{15}\right]$, $105.5\left[\mathrm{C}_{4}\right], 118.5,122.2\left[\mathrm{C}_{13}, \mathrm{C}_{14}\right], 126.6,128.7,129.2,139.7$ $\left[\mathrm{C}_{17}-\mathrm{C}_{22}\right], 140.2,148.9\left[\mathrm{C}_{3}, \mathrm{C}_{5}\right]$, signal for $\left[\mathrm{C}_{11}\right]$ was not observed. IR (ATR) $\mathrm{cm}^{-1}:$ 3087, $2977 \nu(\mathrm{C}-\mathrm{H}), 1551(\nu(\mathrm{C}=\mathrm{C})$, $\nu(\mathrm{C}=\mathrm{N})) \operatorname{ar}, 1448(\delta(\mathrm{C}=\mathrm{C}), \delta(\mathrm{C}=\mathrm{N})) \operatorname{ar}, 1219 \delta(\mathrm{C}-\mathrm{H}) \mathrm{ip}, 700$ $\delta$ (C-H)oop. MS (ESI): $m / z(\%) 401.1(100.0 \%)\left[\mathrm{C}_{18} \mathrm{H}_{22} \mathrm{~N}_{4} \mathrm{ClAg}-\mathrm{Cl}^{-}\right]$.

Dichloro[(S)-3-(2-(3,5-dimethyl-1H-pyrazol-1-yl)ethyl)-1-(1phenylethyl)-1 $H$-imidazol-2-ylidiene- $\left.\kappa^{1} \mathrm{~N}\right]$ palladium(II), (C1). A mixture of $\mathbf{C}_{\mathbf{A g}}(242 \mathrm{mg}, 0.55 \mathrm{mmol})$ and dichloro(1,5cyclooctadiene)palladium(II) $(158 \mathrm{mg}, 0.55 \mathrm{mmol})$ in dichloromethane $(30 \mathrm{~mL})$ was kept under vigorous stirring for 24 hours at room temperature in the dark. The reaction crude was filtered through Celite. Then, the filtrate solvent was evaporated under vacuum and the resulting solid was washed with hexane $(30 \mathrm{~mL})$. The residue was purified by flash column chromatography (silica gel $60 \AA$ ) using ethyl acetate : diethyl ether $4: 1$ as the eluent and then by second column chromatography (silica gel $60 \AA$ ) using dichloromethane: hexane 9:1 as the eluent. The product was obtained as a pale yellow powder. Yield: $133 \mathrm{mg}, 51 \%$.

${ }^{1} \mathrm{H}-\mathrm{NMR}:\left(\mathrm{CDCl}_{3}, 600 \mathrm{MHz}, 298 \mathrm{~K}\right) \delta: 1.61\left[\mathrm{~s}, 3 \mathrm{H}, \mathrm{H}_{6}\right.$ or $\left.\mathrm{H}_{7}\right]$, $2.02\left[\mathrm{br}, 3 \mathrm{H}, \mathrm{H}_{16}\right], 2.70\left[\mathrm{~s}, 3 \mathrm{H}, \mathrm{H}_{6}\right.$ or $\left.\mathrm{H}_{7}\right], 5.71\left[\mathrm{~s}, 1 \mathrm{H}, \mathrm{H}_{4}\right], 5.87$ [br, $\left.2 \mathrm{H}, \mathrm{H}_{9}\right], 6.27\left[\mathrm{br}, 2 \mathrm{H}, \mathrm{H}_{8}\right], 6.08,6.55[2 \mathrm{br}, 1 \mathrm{H}$ each one, $\left.\mathrm{H}_{13}, \mathrm{H}_{14}\right], 6.89$ [br, $\left.\mathrm{H}_{15}\right], 7.39,7.62\left[2 \mathrm{br}, 5 \mathrm{H}, \mathrm{H}_{18}-\mathrm{H}_{22}\right] .{ }^{13} \mathrm{C}\left\{{ }^{1} \mathrm{H}\right\}-$ NMR: $\left(\mathrm{CDCl}_{3}, 150 \mathrm{MHz}, 298 \mathrm{~K}\right) \delta: 10.9,14.5\left[\mathrm{C}_{6}, \mathrm{C}_{7}\right], 19.5\left[\mathrm{C}_{16}\right]$, $50.1\left[\mathrm{C}_{9}\right], 51.1\left[\mathrm{C}_{8}\right], 59.2\left[\mathrm{C}_{15}\right], 106.4\left[\mathrm{C}_{4}\right], 118.5,123.4$ $\left[\mathrm{C}_{13}, \mathrm{C}_{14}\right], 127.4,128.5,128.8\left[\mathrm{C}_{17}-\mathrm{C}_{22}\right], 139.6,144.1\left[\mathrm{C}_{3}, \mathrm{C}_{5}\right]$, signal for $\left[\mathrm{C}_{11}\right]$ was not observed. IR (ATR) $\mathrm{cm}^{-1}: 3097,2978$ $\nu(\mathrm{C}-\mathrm{H}), 1555(\nu(\mathrm{C}=\mathrm{C}), \nu(\mathrm{C}=\mathrm{N})) \operatorname{ar}, 1452(\delta(\mathrm{C}=\mathrm{C}), \delta(\mathrm{C}=\mathrm{N})) \operatorname{ar}$, $1180 \delta(\mathrm{C}-\mathrm{H})$ ip, $694 \delta(\mathrm{C}-\mathrm{H})$ oop. HRMS (ESI): $\mathrm{m} / \mathrm{z} 399.0808$ $\left[\mathrm{C}_{18} \mathrm{H}_{22} \mathrm{~N}_{4} \mathrm{Cl}_{2} \mathrm{Pd}-\mathrm{Cl}^{-}-\mathrm{HCl}\right]$.

Trichloro[(S)-3-(2-(3,5-dimethyl-1H-pyrazol-1-yl)ethyl)-1-(1-phenylethyl)- $\mathbf{H} \mathbf{H}$-imidazol-3-ium-k ${ }^{\mathbf{1}} \mathbf{N}$ ]palladium(II), (C2). A mixture of 1-[2-(3,5-dimethylpyrazol-1-yl)ethyl]-3-((S)-1-phenylethyl)-3Himidazol-1-ium chloride (HLCl, $205 \mathrm{mg}, 0.62 \mathrm{mmol}$ ) and palladium(II) chloride (99.9\%, $110 \mathrm{mg}, 0.62 \mathrm{mmol}$ ) in acetonitrile $(20 \mathrm{~mL})$ was kept under vigorous stirring for 24 hours at room temperature. Then, the solution was filtered through Celite. The solvent volume was decreased to $c a .2 \mathrm{~mL}$ and diethyl ether $(30 \mathrm{~mL})$ was added to induce precipitation. The orange powder was filtered and washed with diethyl ether $(3 \times 30 \mathrm{~mL})$, and dried under vacuum. The product was obtained as an 
orange powder. The single crystals for X-ray diffraction were obtained by slow evaporation of a concentrated acetonitrile solution of the complex at room temperature. Yield: $222 \mathrm{mg}, 70 \%$.

Anal. calcd for $\mathrm{C}_{18} \mathrm{H}_{23} \mathrm{~N}_{4} \mathrm{Cl}_{3} \mathrm{Pd}$ : C, 42.54; H, 4.56; N, 11.02. Found: C, 42.03; H, 4.62; N, 10.76. ${ }^{1} \mathrm{H}-\mathrm{NMR}$ : (DMSO-d6, $360 \mathrm{MHz}, 298 \mathrm{~K}) \delta: 1.80\left[\mathrm{~d}, 3 \mathrm{H},{ }^{3} J=7.0 \mathrm{~Hz}, \mathrm{H}_{16}\right], 1.98[\mathrm{~s}, 3 \mathrm{H}$, $\mathrm{H}_{6}$ or $\left.\mathrm{H}_{7}\right], 2.01\left[\mathrm{~s}, 3 \mathrm{H}, \mathrm{H}_{6}\right.$ or $\left.\mathrm{H}_{7}\right], 4.38\left[\mathrm{t}, 2 \mathrm{H},{ }^{3} J=5.0 \mathrm{~Hz}, \mathrm{H}_{9}\right]$, $4.54\left[\mathrm{t}, 2 \mathrm{H},{ }^{3} \mathrm{~J}=5.0 \mathrm{~Hz}, \mathrm{H}_{8}\right], 5.75\left[\mathrm{~s}, 1 \mathrm{H}, \mathrm{H}_{4}\right], 5.79\left[\mathrm{br}, 1 \mathrm{H}, \mathrm{H}_{15}\right]$, $7.32,7.40\left[2 \mathrm{~m}, 5 \mathrm{H}, \mathrm{H}_{18}-\mathrm{H}_{22}\right], 7.64,7.83$ [2br, $1 \mathrm{H}$ each one, $\mathrm{H}_{13}, \mathrm{H}_{14}$ ], 9.03 [s, $1 \mathrm{H}, \mathrm{H}_{11}$ ]. ${ }^{13} \mathrm{C}\left\{{ }^{1} \mathrm{H}\right\}-N M R:$ (DMSO-d6, $91 \mathrm{MHz}$, $298 \mathrm{~K}) \delta: 10.2,13.3\left[\mathrm{C}_{6}, \mathrm{C}_{7}\right], 20.6\left[\mathrm{C}_{16}\right], 47.1\left[\mathrm{C}_{9}\right], 48.9\left[\mathrm{C}_{8}\right], 58.5$ $\left[\mathrm{C}_{15}\right], 105.0\left[\mathrm{C}_{4}\right], 121.3,123.2\left[\mathrm{C}_{13}, \mathrm{C}_{14}\right], 126.4,128.7,129.0$, $139.4\left[\mathrm{C}_{17}-\mathrm{C}_{22}\right], 135.8\left[\mathrm{C}_{11}\right], 139.4,146.9\left[\mathrm{C}_{3}, \mathrm{C}_{5}\right] . \mathrm{IR}$ (ATR) $\mathrm{cm}^{-1}$ : 3091, $2984 \nu(\mathrm{C}-\mathrm{H}), 1555(\nu(\mathrm{C}=\mathrm{C}), \nu(\mathrm{C}=\mathrm{N}))$ ar, 1453 $(\delta(\mathrm{C}=\mathrm{C}), \delta(\mathrm{C}=\mathrm{N}))$ ar, $1152 \delta(\mathrm{C}-\mathrm{H})$ ip, $704 \delta(\mathrm{C}-\mathrm{H})$ oop. MS (ESI): $m / z(\%) 399.1(100.0 \%)\left[\mathrm{C}_{18} \mathrm{H}_{23} \mathrm{~N}_{4} \mathrm{Cl}_{3} \mathrm{Pd}-\mathrm{Cl}^{-}-2 \mathrm{HCl}\right], 437.1$ (26.5\%) $\left[\mathrm{C}_{18} \mathrm{H}_{23} \mathrm{~N}_{4} \mathrm{Cl}_{3} \mathrm{Pd}-\mathrm{Cl}^{-}-\mathrm{HCl}\right], 473.0 \quad(25.7 \%)$ $\left[\mathrm{C}_{18} \mathrm{H}_{23} \mathrm{~N}_{4} \mathrm{Cl}_{3} \mathrm{Pd}-\mathrm{Cl}^{-}\right]$.

\section{Synthesis of Pd/L and Pd/HLCl nanoparticles}

The general procedure for the preparation of palladium nanoparticles is detailed through the case of $[\mathbf{L}] /[\mathrm{Pd}]=0.5$ (Fig. 2a and Scheme 1). The procedure was similar for all other samples.

$\left[\mathrm{Pd}_{2}(\mathrm{dba})_{3}\right](200 \mathrm{mg}, 0.22 \mathrm{mmol})$ and $\mathbf{L}(28.6 \mathrm{mg}$, $0.11 \mathrm{mmol}$ ) were dissolved in a Fisher-Porter reactor in previously degassed anhydrous dichloromethane $(200 \mathrm{~mL})$ under argon at $196 \mathrm{~K}$. The mixture was pressurized under 3 bar of dihydrogen and kept at room temperature under vigorous stirring. The color of the solution turned from purple to black after $1 \mathrm{~h}$. The hydrogen pressure and the temperature were maintained for $18 \mathrm{~h}$. After that period of time, the colloidal solution was black and homogeneous. Hydrogen was evacuated and a drop of the crude colloidal solution was deposited under argon on a holey carbon-covered copper grid using filter paper under the grid for TEM and SEM analysis. Then, the colloidal solution was concentrated to $c a .10 \mathrm{~mL}$. The addition of cold pentane $(20 \mathrm{~mL})$ allowed the precipitation of the particles as a black solid, which was washed with pentane $(3 \times 20 \mathrm{~mL})$ and dried under reduced pressure. The filtered pentane was slightly yellow due to dba elimination. This was corroborated by ${ }^{1} \mathrm{H}-\mathrm{NMR}$ experiments of the dried pentane solution. N1 Anal. found (wt\%): Pd, 66.0; N, 5.34 for a stoichiometry of $\mathrm{Pd}_{561} \mathrm{~L}_{37}$. IR (ATR, $\mathrm{cm}^{-1}$ ): 3026, $2939 \nu(\mathrm{C}-\mathrm{H}), 1564$ $(\nu(\mathrm{C}=\mathrm{C}), \nu(\mathrm{C}=\mathrm{N}))$ ar, $1462(\delta(\mathrm{C}=\mathrm{C}), \delta(\mathrm{C}=\mathrm{N}))$ ar, $700 \delta(\mathrm{C}-\mathrm{H})$ oop. N2: anal. found (wt\%): $\mathrm{Pd}, 83.0 ; \mathrm{N}, 2.90$ for a stoichiometry of $\mathrm{Pd}_{1415} \mathrm{HLCl}_{93}$. IR $\left(\mathrm{KBr}, \mathrm{cm}^{-1}\right)$ : 3019, $2960 \nu(\mathrm{C}-\mathrm{H})$, $1563(\nu(\mathrm{C}=\mathrm{C}), \nu(\mathrm{C}=\mathrm{N})) \operatorname{ar}, 1456(\delta(\mathrm{C}=\mathrm{C}), \delta(\mathrm{C}=\mathrm{N}))$ ar, 1137 $\delta(\mathrm{C}-\mathrm{H})$ ip.

\section{Crystal structure determination of $\mathrm{C2}$}

Crystallographic data for compound $\mathbf{C 2}$ were collected at low temperature $(180 \mathrm{~K})$ on a Bruker Kappa Apex II diffractometer using graphite-monochromated Mo-K $\alpha$ radiation $(\lambda=$ $0.71073 \AA$ ) and equipped with an Oxford Cryosystems
Cryostream Cooler device. Crystallographic data for $\mathbf{C} 2$ can be gathered in the ESI, Tables S1 and S2. $\dagger$

The structures have been solved by Direct Methods using SIR92, ${ }^{33}$ and refined by means of least-squares procedures on $F^{2}$ with the aid of the program SHELXL97 $7^{34}$ included in the software package WinGX version $1.63 .^{35}$ The atomic scattering factors were taken from International tables for X-ray crystallography. ${ }^{36,37}$ All hydrogen atoms were placed geometrically, and refined by using a riding model. All non-hydrogen atoms were anisotropically refined, and in the last cycles of refinement a weighing scheme was used, where weights are calculated from the following formula: $\mathrm{w}=1 /\left[\sigma^{2}\left(F_{\mathrm{o}}{ }^{2}\right)+(a P)^{2}+b P\right]$ where $P=\left(F_{\mathrm{o}}{ }^{2}+2 F_{\mathrm{c}}{ }^{2}\right) / 3$.

Crystallographic data for the structural analyses have been deposited at the Cambridge Crystallographic Data Centre, CCDC, with reference number 1432563 (C2). $\dagger$

\section{Catalytic experiments}

The quantification of the catalytic reactions was carried out in an HP5890 Hewlett Packard gas chromatograph equipped with a FID detector and an HP-5 column (5\% diphenylpolysiloxane and $95 \%$ dimethylpolysiloxane). The products obtained in the catalytic reactions were identified using a G1800A Hewlett Packard gas chromatograph with an electron impact ionization detector and a HP-5 column (5\% diphenylpolysiloxane and 95\% dimethylpolysiloxane). The mass spectra of the catalytic products are in agreement with those published in the literature. ${ }^{38,39}$

\section{Suzuki-Miyaura reactions}

In a two-neck round-bottom flask fitted with a reflux condenser and a septum, 4-halogenotoluene (2.5 mmol), phenylboronic acid $(3.125 \mathrm{mmol}),{ }^{t} \mathrm{BuOK}(5.0 \mathrm{mmol})$, and naphthalene $(0.5 \mathrm{mmol})$ as internal standards were dissolved in $\mathrm{DMF} / \mathrm{H}_{2} \mathrm{O}$ (10 mL, 4/1). Next, the palladium organometallic complex $\left(1 \times 10^{-3} \mathrm{mmol}\right)$ or palladium nanoparticles $\left(1 \times 10^{-3} \mathrm{mmol}\right.$ Pd atoms) were added. The solution was vigorously stirred and heated at $100{ }^{\circ} \mathrm{C}$ for $6 \mathrm{~h}$ under nitrogen. Then, the reaction crude was cooled to room temperature and the products were extracted with a mixture of diethyl ether/brine $(20 \mathrm{~mL}, 1 / 1)$. The organic phase was analyzed by GC and GC-MS.

\section{Conclusions}

A new hybrid pyrazole-imidazol-2-ylidene ligand, 1-[2-(3,5-dimethylpyrazol-1-yl)ethyl]-3-((S)-1-phenylethyl)-3H-imidazol-2ylidene $(\mathbf{L})$, has been synthesized for the first time and proved to effectively stabilize small and isolated palladium(0) nanoparticles. A comparison with its counterpart HLCl as a stabilizer led to badly stabilized NPs which evidenced that the coordination of the ylidene group is a key factor in the stabilization process of the colloidal system. The successful preparation and complete characterization of molecular $\mathrm{Pd}(\mathrm{II})$ coordination compounds with the same ligands confirmed a chelated coordination mode through the pyrazolic nitrogen 
and the ylidene group for $\mathbf{L}$ but a terminal monodentate mode through pyrazolic nitrogen for HLCl. From our previous research with carbene or pyrazole-containing ligands as stabilizers, we can conclude that similar coordination modes of $\mathbf{L}$ and HLCl here take place for both the Pd NP particles and Pd complexes respectively. As a consequence, the coordination of $\mathbf{L}$ is stronger and leads to nanoparticles with well-controlled size.

All these systems have been tested in catalytic $\mathrm{C}-\mathrm{C}$ coupling reactions. For colloidal systems (N1 and N2), we observed an improving effect, in terms of chemoselectivity and yield, of $\mathbf{L}$ containing NPs (N1) with respect to HLCl containing NPs (N2) as a result of the different coordination modes of the carbene group to the surface of the NPs. Interestingly, these systems are the only ones able to achieve the $\mathrm{C}-\mathrm{C}$ homocoupling reaction between two molecules of bromoarenes or the complete dehalogenation reaction of iodoarenes. The Suzuki-Miyaura reaction is favored with the Pd molecular complexes.

Taking into account the advantages of the organometallic approach and the different attributes of these catalysts, we believe that these materials could find practical uses in $\mathrm{C}-\mathrm{C}$ coupling reactions in the future.

\section{Conflicts of interest}

There are no conflicts to declare.

\section{Acknowledgements}

Support from MINECO (CTQ2015-64261-R and CTQ201564436-P) is gratefully acknowledged. F. G. V. and J. DeT. acknowledge the Universitat Autònoma de Barcelona for their pre-doctoral grants. J. G.-A. acknowledges the Serra Húnter Program. The authors thank the Microscopy Service of the Universitat Autònoma de Barcelona for technical assistance with TEM and HR-TEM. CNRS is also thanked through the LTPMM-LEA 368 action.

\section{Notes and references}

1 (a) M. N. Hopkinson, C. Richter, M. Schedler and F. Glorius, Nature, 2014, 510, 485-496; (b) F. Glorius, Top. Organomet. Chem., 2006, 21, 1-20; (c) J. A. M. Lummiss, C. S. Higman, D. L. Fyson, R. McDonald and D. E. Fogg, Chem. Sci., 2015, 6, 6739-6746.

2 N. Hadei, E. A. B. Kantchev, C. J. O'Brien and M. G. Organ, Org. Lett., 2005, 7, 1991.

3 (a) G. D. Frey, V. Lavallo, B. Donnadieu, W. W. Schoeller and G. Bertrand, Science, 2007, 316, 439-441; (b) Y. Wang, Y. Xie, P. Wei, R. B. King, H. F. Schaefer III, P. v. R. Schleyer and G. Robinson, Science, 2008, 321, 1069-1071.

4 (a) A. V. Zhukhovitskiy, M. J. MacLeod and J. A. Johnson, Chem. Rev., 2015, 115, 11503-11532; (b) P. Lara, O. RivadaWheelaghan, S. Conejero, K. Philippot and B. Chaudret,
Angew. Chem., Int. Ed., 2011, 50, 12080-12084; (c) P. Lara, A. Suárez, V. Colliere, K. Philippot and B. Chaudret, ChemCatChem, 2014, 6, 87-90; (d) J. Vignolle and T. D. Tilley, Chem. Commun., 2009, 46, 7230-7232; (e) E. C. Hurst, K. Wilson, I. J. S. Fairlamb and V. Chechik, New J. Chem., 2009, 33, 1837-1840; (f) D. González-Gálvez, P. Lara, O. Rivada-Wheelaghan, S. Conejero, B. Chaudret, K. Philippot and P. W. N. M. van Leeuwen, Catal. Sci. Technol., 2013, 3, 99-105; $(g)$ E. A. Baquero, S. Tricard, J. C. Flores, E. de Jesús and B. Chaudret, Angew. Chem., Int. Ed., 2014, 53, 13220-13224; (h) A. Ferry, K. Schaepe, P. Tegeder, C. Richter, K. M. Chepiga, B. J. Ravoo and F. Glorius, ACS Catal., 2015, 5, 5414-5420; (i) L. M. Martínez-Prieto, A. Ferry, P. Lara, C. Richter, K. Philippot, F. Glorius and B. Chaudret, Chem. - Eur. J., 2015, 21, 17495-17502; (j) C. Richter, K. Schaepe, F. Glorius and B. J. Ravoo, Chem. Commun., 2014, 50, 32043207; (k) L. M. Martínez-Prieto, A. Ferry, C. Richter, P. Lecante, K. Philippot, F. Glorius and B. Chaudret, Chem. Commun., 2016, 52, 4768-4771; (l) L. M. Martínez-Prieto, C. Urbaneja, P. Palma, J. Cámpora, K. Philippot and B. Chaudret, Chem. Commun., 2015, 51, 4647-4650.

5 M. Albrecht, Adv. Organomet. Chem., 2014, 62, 111158.

6 (a) P. Lara, K. Philippot, L. M. Lacroix, S. Lachaize, N. Liakakos, K. Soulantica and B. Chaudret, Organometallic Nanoparticles, in Advances in Organometallic Chemistry: The Silver/Gold Jubilee International Conference on Organometallic Chemistry Celebratory Book, ed. A. J. L. Pombeiro, Wiley VCH, Weinheim, 2013, ch. 31, pp. 421-436; (b) S. Kinayyigit and K. Philippot, Organometallic Approach for the Synthesis of Noble Metal Nanoparticles: Towards Application in Colloidal and Supported Nanocatalysis, in Metal Nanoparticles for Catalysis: Advances and Applications, ed. T. Tao, RSC, 2014, ch. 4, pp. 47-82; (c) K. An and G. A. Somorjai, ChemCatChem, 2012, 4, 1442; (d) N. J. Costa, M. Guerrero, V. Colliere, E. Teixeira-Neto, R. Landers, K. Philippot and L. M. Rossi, ACS Catal., 2014, 4, 1735-1742.

7 C. Amiens, D. Ciuculescu-Pradines and K. Philippot, Coord. Chem. Rev., 2016, 38, 409-432.

8 (a) K. Philippot and P. Serp, Concepts in Nanocatalysis, in Nanomaterials in Catalysis, ed. P. Serp and K. Philippot, Wiley-VCH, Weinheim, 2013, ch. 1, pp. 1-54; (b) T. Ayvali and K. Philippot, On the use of Organometallic Concepts for the Synthesis of Nanocatalysts, in New Materials for Catalytic Applications, ed. E. Kemnitz and V. Parvulescu, Elsevier, 2016, ch. 3, pp. 41-79; (c) A. Roucoux, J. Schulz and H. Patin, Chem. Rev., 2002, 102, 3757-3778; (d) M. Guerrero, N. T. T. Chau, S. Noel, A. DenicourtNowicki, F. Hapiot, A. Roucoux, E. Montflier and K. Philippot, Curr. Org. Chem., 2013, 17, 364-399; (e) B. Chaudret, M. Gómez and K. Philippot, Top. Catal., 2013, 56, 1153; (f) D. Wang and D. Astruc, Chem. Rev., 2014, 114, 6949-6985. 
9 (a) A. Kolmakov, X. Chen and M. J. Moskovits, Nanosci. Nanotechnol., 2008, 8, 111-121; (b) M. Guerrero, N. J. S. Costa, L. L. R. Vono, L. M. Rossi, E. V. Gusevskaya and K. Philippot, J. Mater. Chem. A, 2013, 1, 1441-1449.

10 A. Bej, K. Ghosh, A. Sarkar and D. W. Knight, RSC Adv., 2016, 6, 11446-11453.

11 S. Kotha, K. Lahiri and D. Kashinath, Tetrahedron, 2002, 58, 9633-9695.

12 A. Ganesan, Drug Discovery Today, 2001, 6, 238.

13 D. Astruc, C. Ornelas, A. K. Diallo and J. Ruiz, Molecules, 2010, 15, 4947-4960.

14 D. Peral, F. Gómez-Villarraga, X. Sala, J. Pons, J. C. Bayon, J. Ros, M. Guerrero, L. Vendier, P. Lecante, J. García-Antón and K. Philippot, Catal. Sci. Technol., 2013, 3, 475-489.

15 C. Amiens, B. Chaudret, D. Ciuculescu-Pradines, V. Collière, K. Fajerwerg, P. Fau, M. Kahn, A. Maisonnat, K. Soulantica and K. Philippot, New J. Chem., 2013, 37, 3374-3401.

16 J. Deng, H. Gao, F. Zhu and Q. Wu, Organometallics, 2013, 32, 4507-4515.

17 T. L. Hwang and A. J. Shaka, J. Am. Chem. Soc., 1992, 114, 3157-3159.

18 A. D. Bain, Prog. Nucl. Magn. Reson. Spectrosc., 2003, 43, 63-103.

19 Z. A. Savel'eva, L. A. Glinskaya, S. A. Popov, R. F. Klevtsova, A. V. Tkachev and S. V. Larionov, Russ. J. Coord. Chem., 2009, 35, 668-673.

20 H. M. Lee, P. L. Chiu, C.-H. Hu, C.-L. Lai and Y.-C. Chou, J. Organomet. Chem., 2005, 690, 403-414.

21 G. Aragay, J. Pons, J. García-Antón, X. Solans, M. FontBardia and J. Ros, J. Organomet. Chem., 2008, 693, 3396-3404.

22 N. Miyaura, K. Yamada and A. Suzuki, Tetrahedron Lett., 1979, 36, 3437-3440.

23 N. Miyaura and A. Suzuki, Chem. Rev., 1995, 95, 2457-2483.

24 S. J. Blanksby and G. B. Ellison, Acc. Chem. Res., 2003, 36, 255-263.

25 A. V. Astakhov, O. V. Khazipov, A. Y. Chernenko, D. V. Pasyukov, A. S. Kashin, E. G. Gordeev, V. N. Khrustalev, V. M. Chernyshev and V. P. Ananikov, Organometallics, 2017, 36, 1981-1992.

26 (a) P. J. Ellis, I. J. S. Fairlamb, S. F. J. Hackett, K. Wilson and A. F. Lee, Angew. Chem., Int. Ed., 2010, 49, 1820-1824; (b) R. Narayanan and M. A. El-Sayed, J. Phys. Chem. B, 2004, 108, 8572-8580; (c) R. Narayanan and M. A. El-Sayed, J. Am. Chem. Soc., 2003, 125, 8340-8347; (d) A. F. Lee, P. J. Ellis, I. J. S. Fairlamb and K. Wilson, Dalton Trans., 2010, 1047310482; (e) C. Sánchez-Sánchez, N. Orozco, J. P. Holgado, S. K. Beumont, G. Kyriakou, D. J. watson, A. R. González-
Eripe, L. Feria, J. Fernández-Sanz and R. M. Lambert, J. Am. Chem. Soc., 2014, 137, 940-947; (f) V. K. Kanuru, G. Kyriakou, S. K. Beaumont, A. C. Papageorgiou, D. J. Watson and R. M. Lambert, J. Am. Chem. Soc., 2010, 132, 8081-8086; $(g)$ C. Sánchez-Sánchez, F. Yubero, A. R. González-Elipe, L. Feria, J. Fernández-Sanz and R. M. Lambert, J. Phys. Chem. C, 2014, 118, 11677-11684; (h) F. Wang, C. Li, L.-D. Sun, H. Wu, T. Ming, J. Wang, J. C. Yu and C.-H. Yan, J. Am. Chem. Soc., 2011, 133, 11061111; (i) F. Wang, C. Li, H. Chen, R. Jiang, L.-D. Sun, Q. Li, J. Wang, J. C. Yu and C.-H. Yan, J. Am. Chem. Soc., 2013, 135, 5588-5601.

27 (a) Z. Niu, Q. Peng, Z. Zhuang, W. He and Y. Li, Chem. Eur. J., 2012, 18, 9813-9817; (b) D. B. Pacardo, J. M. Slocik, K. C. Kirk, R. R. Naik and M. R. Knecht, Nanoscale, 2011, 3, 2194-2201; (c) A. V. Gaikwad, A. Holuigue, M. B. Thathagar, J. E. ten Elshof and G. Rothenberg, Chem. - Eur J., 2007, 13, 6908-6913; (d) M. T. Reetz and E. Westermann, Angew. Chem., Int. Ed., 2000, 39, 165-168; (e) J. G. de Vries, Dalton Trans., 2006, 421-429.

28 G. M. Whitesides, M. Hackett, R. L. Brainard, J. P. P. M. Lavalleye, A. F. Sowinski, A. N. Izumi, S. S. Moore, D. W. Brown and E. M. Staud, Organometallics, 1985, 4, 1819-1830.

29 R. L. Oliveira, W. He, R. J. M. Klein Gebbink and K. P. de Jong, Catal. Sci. Technol., 2015, 5, 1919-1928.

30 S. Komiya, in Synthesis of Organometallic Compounds: A Practice Guide, Board, New York, 1997.

31 D. Drew and J. R. Doyle, in Inorganic Syntheses, 28 (Reagents Transition Met. Complex Organomet. Synth.), 1990, pp. 346-349.

32 H. Konishi, T. Ueda, T. Muto and K. Manabe, Org. Lett., 2012, 14, 4722-4725.

33 A. Altomare, G. Cascarano, C. Giacovazzo and A. Guagliardi, J. Appl. Crystallogr., 1993, 26, 343-350.

34 G. M. Sheldrick, Acta Crystallogr., Sect. A: Fundam. Crystallogr., 2008, 64, 112-122.

35 L. J. Farrugia, Appl. Crystallogr., 1999, 32, 837-838.

36 T. Hahn, in International Tables for Crystallography, Volume A, Kluwer Academic Publishers, Dordrecht, The Netherlands, 1995.

37 A. J. C. Wilson, in International Tables for Crystallography, Volume C, Kluwer Academic Publishers, Dordrecht, The Netherlands, 1995.

38 X. Xu, D. Cheng and W. Pei, J. Org. Chem., 2006, 71, 66376639.

39 I. J. S. Fairlamb, A. R. Kapdi and A. F. Lee, Org. Lett., 2004, 6, 4435-4438. 